\title{
Mise au point : rayonnement solaire absorbé ou intercepté par un couvert végétal
}

\author{
C. Varlet-Grancher ${ }^{1}$, G. Gosse ${ }^{2}$, M. Chartier ${ }^{2}$, H. Sinoquet ${ }^{3}$, R. Bonhomme ${ }^{3}$ et J.M. Allirand ${ }^{2}$ \\ 1 INRA, Station d'Ecophysiologie des Plantes Fourragères, Centre de Recherches Poitou-Charentes, F 86600 Lusignan, France \\ 2 INRA, Station de Bioclimatologie, Centre de recherches Paris-Grignon - $F 78850$ Thiverval-Grignon, France \\ ${ }_{3}$ INRA, Station Agropédoclimatique, Centre de recherches des Antilles et de la Guyane, B.P. 1232 - F 97184 Pointe-à-Pitre cedex
}

(reçu le 12 septembre 1988, accepté le 3 mars 1989)

Résumé - Cet article rappelle les principales définitions et méthodes de mesure utilisées dans les études du bilan radiatif solaire d'un couvert végétal.

Le rayonnement solaire reçu par un couvert végétal peut être caractérisé par :

- le rayonnement global (ou total): $\mathrm{Rg}_{0}$ mesuré par l'éclairement énergétique des rayonnements direct et diffus,

- le rayonnement utile à la photosynthèse : PAR énergétique $\mathrm{EPAR}_{0}$ soit par l'éclairement quantique $\mathrm{QPAR}_{0}$.

Le rayonnement absorbé représente la différence entre les rayonnements reçus (rayonnement incident et rayonnement réfléchi par le sol) et les rayonnements "perdus" (rayonnement réfléchi par l'ensemble sol-culture et rayonnement transmis au sol). Certains auteurs avec Gallagher et Biscoe (1978) négligent le rayonnement réfléchi par le sol dans le rayonnement absorbé alors que de nombreux travaux considèrent seulement le rayonnement intercepté: bilan entre le rayonnement incident et le rayonnement transmis. En rapportant les rayonnements absorbé ou intercepté au rayonnement incident on peut définir les propriétés optiques du couvert végétal (réflectance sol, réflectance sol-culture, transmittance culture) et calculer les efficiences de l'absorption ou de l'interception.

Les principales méthodes qui permettent d'obtenir les différentes composantes du bilan radiatif sont rappelées; les plus grandes difficultés concernent le rayonnement transmis qui peut être mesuré par un "réseau» de capteurs ponctuels ou par un capteur déplacé linéairement dans la culture, ou encore par des capteurs linéaires (les références des principaux capteurs commercialisés sont indiquées).

Des relations: $\varepsilon=\varepsilon_{\max }[1-\exp (-K x I F)]$ entre les efficiences $\varepsilon$ (absorption ou interception) et l'indice foliaire IF sont souvent utilisés pour calculer le rayonnement absorbé ou intercepté (produit de l'efficience et du rayonnement incident) par la culture au cours de son cycle. Nous avons regroupé les valeurs du coefficient $\mathrm{K}$ obtenues pour différentes espèces et par divers auteurs.

rayonnement solaire global - rayonnement utile à la photosynthèse - bilan radiatif solaire - efficience de l'absorption du rayonnement solaire - efficience de l'interception du rayonnement solaire

Summary - Solar radiation absorbed or intercepted by a crop. This paper summarizes some methods and definitions used to study the solar radiation balance of a crop.

Solar radiation can be characterized by:

- global (or total) solar radiation: $R g_{o}$ measured as short wave energy flux (or energy irradiance) from direct and diffuse radiations,

- photosynthetically active radiation $P A R_{0}$, measured as energy flux (or energy irradiance) EPAR $R_{0}$, or photon flux (or quantum irradiance) $Q P A R_{0}$ for radiations within 400-700 $\mathrm{nm}$ band.

Crop solar radiation balance can be established as absorbed or intercepted radiation. Absorbed radiation is the balance between received radiations (incident and soil reflected radiations) and "lost" radiations (crop reflected and transmitted radiations). Soil reflection is neglected in Gallagher and Biscoe (1978) formulae. Intercepted radiation is the difference between incident and transmitted radiation. The fractions of absorbed and intercepted photosynthetically active radiation are close but the fractions of absorbed or intercepted radiation are different between PAR and total radiation.

The main methods to obtain radiation balance components are given; the main difficulty is to measure transmitted radiation. This component can be obtained from a randomly located set of several stationnary sensors or a moving sensor across the crop, or a linear sensor (some manufactured radiation sensors are given). Some values of interception (or absorption) coefficient $K$ from the relationships between the fraction of intercepted (or absorbed) radiation and leaf area are given.

total solar radiation - PAR - solar radiation balance - efficiency of absorbed radiation - efficiency of intercepted radiation 


\section{Introduction}

Depuis longtemps, différents auteurs ont essayé d'analyser la croissance en matière sèche d'un couvert végétal par rapport au rayonnement solaire (Kamel, 1958; Shibles et Weber, 1965; Monteith, 1972 par exemple). Ces dernières années, l'utilisation de cette méthode s'est généralisée et de nombreux auteurs (Bonhomme et al., 1982; Gosse et al., 1984; Howell et Musick, 1984; Martin, 1986; etc.) présentent des relations entre la production de matière sèche et la quantité de rayonnement solaire absorbée ou interceptée par une culture. Dans ces travaux, les bilans radiatifs considérés, tout comme les méthodes et les techniques utilisées, sont rarement définis avec clarté et diffèrent souvent entre les auteurs. II est donc très difficile de comparer les résultats (Gosse et al., 1986; Russell et al., 1988). C'est pourquoi il nous a semblé important de faire une revue de ces techniques en relation avec les types de bilan radiatif et la caractérisation du rayonnement solaire qui peuvent être considérés. Ce travail concerne essentiellement les cultures herbacées, en conditions naturelles, cependant quelques exemples de résultats obtenus sur des plantes ligneuses ont aussi été utilisés.

\section{Bilan radiatif solaire d'un couvert végétal}

\section{Caractérisation du rayonnement solaire}

Le rayonnement solaire reçu à la surface du sol sur un plan horizontal correspond aux rayonnements provenant directement du soleil (composante directe) selon une direction donnée par sa position (azimut et hauteur), et aux rayonnements diffusés, absorbés puis rediffusés pendant leur traversée de l'atmosphère (composante diffuse) qui arrivent de toutes les directions ( $2 \pi$ stéradians). Le rayonnement solaire global représente donc la somme des rayonnements direct et diffus dans la gamme de longueur d'onde 300-3 $000 \mathrm{~nm}$. Toutes les radiations du spectre solaire ne peuvent être utilisées par les organes chlorophylliens. La conversion de l'énergie des photons incidents en énergie chimique par l'appareil photosynthétique d'une feuille n'est réalisée que pour les rayonnements ayant une longueur d'onde comprise entre 350 et $750 \mathrm{~nm}$ environ, et avec une efficacité très variable dans cet intervalle. Ainsi de nombreux auteurs (Gabrielsen, 1940; Gaastra, 1959; Nichiporovich, 1960; McCree, 1966 parmi les plus importants) ont posé le problème de la définition du rayonnement utile pour la photosynthèse.

Depuis les travaux de McCree $(1972 ; 1973)$, la gamme $400-700 \mathrm{~nm}$ est communément admise pour définir le rayonnement utile à la photosynthèse, même si les spectres d'action peuvent présenter quelques divergences entre espèces (notamment entre plantes ligneuses et herbacées; Clark et Lister, 1975; Inada, 1978). Le sigle PAR (Photosynthetically Active Radiation) est actuellement le plus répandu pour désigner le rayonnement utile à la photosynthèse (RPA : Rayonnement Photosynthétiquement Actif ou RUP : Rayonnement Utile à la Photosynthèse, en français). Les travaux de McCree ont montré aussi une meilleure proportionnalité entre l'intensité de la photosynthèse et le PAR lorsque celuici est caractérisé en nombre de photons plutôt que par son énergie.

Cependant, cette caractérisation reste imparfaite notamment pour des sources artificielles à spectre étroit (Sager et al., 1982). L'expression du PAR en énergie est néanmoins satisfaisante pour les variations de composition spectrale rencontrées en conditions naturelles (Varlet-Grancher et al., 1981). Le rayonnement solaire peut donc être caractérisé par trois grandeurs différentes:

- le rayonnement global ou total exprimé en énergie,

- le rayonnement utile à la photosynthèse exprimé en énergie,

- le rayonnement utile à la photosynthèse exprimé en nombre de photons.

Les expressions en énergie correspondent à des éclairements énergétiques d'une unité de surface horizontale (Perrin de Brichambaut, 1963; Robinson, 1966) et sont mesurées en watt par mètre carré $\left(\mathrm{W} / \mathrm{m}^{2}\right)$ selon le système international. L'intégration de l'éclairement (quantité d'éclairement) est exprimée en joules par mètre carré $\left(\mathrm{J} / \mathrm{m}^{2}\right)$ ou en Mégajoules par mètre carré $\left(\mathrm{MJ} / \mathrm{m}^{2}\right)$ selon la période considérée (heure, journée, décade...). Les symboles les plus courants pour le rayonnement global (Total irradiance, Radiant flux density ou Solar irradiance pour les Anglo-Saxons) sont I, S, K, SI,SR ou encore G et $\mathrm{Rg}$ surtout dans les travaux français. Pour désigner le PAR en énergie ou en photons, ces mêmes symboles ont parfois été affectés des indices $v$ ou $p$.

Dans les recommandations de Shibles (1976), reprises par de nombreuses revues, l'éclairement énergétique PAR est désigné par le terme Photosynthetic irradiance (de symbole $\mathrm{PI}$ en $\mathrm{W} / \mathrm{m}^{2}$ ), alors que l'expression Photosynthetic photon flux density (PPFD) correspond au nombre de photons incidents utiles à la photosynthèse reçus par unité de temps sur une unité de surface horizontale.

Pour exprimer ce nombre de photons, différents auteurs (Anderson, 1971; Shibles, 1976 par 
exemple) et le premier constructeur d'un capteur spécifique (LI-COR) ont recommandé l'emploi de l'Einstein. En fait, cette utilisation ne correspond pas à la définition exacte de cette unité (INCOLL et al., 1977; Savage, 1979) et le PPFD doit être exprimé (selon le système international) en moles de photons par $\mathrm{m}^{2}$ et seconde ou en $\mu \mathrm{mol} . \mathrm{m}^{-2} \mathrm{~s}^{-1}$ (Savage, 1982; Krizek et McFarlane, 1983).

Bien que très courantes dans la littérature scientifique, ces expressions (PI et surtout PPFD) ont été remises en cause par quelques auteurs (Mohr et Schafer, 1979; McLaren, 1980; Bell et Rose, 1981). La terminologie proposée récemment par Holmes et al. (1985) distingue bien le rayonnement solaire reçu en un point (récepteur sphérique), du rayonnement reçu sur une surface plane, en définissant les conditions de mesure.

Ainsi, pour une surface horizontale, avec des capteurs ayant un angle d'ouverture de $2 \pi$ stéradians et corrigés en cosinus pour les rayons non perpendiculaires, ces auteurs utilisent les termes: Flux d'énergie (Energy Flux) en $\mathrm{Wm}^{-2}$ et Flux de photons (Photon Flux) en mol. $\mathrm{m}^{-2} \mathrm{~s}^{-1}$, auxquels il suffit d'ajouter «du rayonnement utile à la photosynthèse" pour caractériser le PAR.

Ces désignations n'ont pas, jusqu'à présent, de reconnaissance internationale officielle et elles seront peut-être remises en question par d'autres auteurs; cependant, elles apparaissent comme les plus simples et les plus précises de toute la bibliographie actuelle (voir la revue de Sheehy, 1985). II faut remarquer que dans ces mêmes conditions la terminologie française (Baille et al., 1982) peut être aussi simple avec les termes: éclairement énergétique utile à la photosynthèse et éclairement quantique utile à la photosynthèse. Nous proposons de garder cette double terminologie (Energy Flux, «Eclairement énergétique"...) selon le langage utilisé et d'adopter les symboles correspondants: EPAR et QPAR. II faut noter cependant que les principales revues de physiologie végétale ne différencient pas la géométrie de la surface réceptrice et expriment l'éclairement par photon fluence rate ou energy fluence rate.

Les unités photométriques : éclairement lumineux (mesuré en lux) devraient être abandonnées pour les études de la photosynthèse ou de la production végétale. Le lux a été défini à partir de la sensibilité de l'œil humain (mesures effectuées sur 52 Américains en 1923, Incoll et al., 1977) et n'a aucun rapport avec les mécanismes photosynthétiques. Toutefois, comme un nombre important de résultats a été exprimé autrefois avec cette unité, et que les éclairagistes l'utilisent, il peut être intéressant de disposer de coefficients de conversion, même approximatifs, avec des unités correctes (cf. travail de Thimijan et Heins, 1983).

\section{Bilan radiafif d'un couvert végétal : rayonnement absorbé et rayonnement intercepté}

Le couvert végétal n'absorbe pas tout le rayonnement solaire qu'il reçoit : une partie est réfléchie vers l'atmosphère et une autre est transmise au sol qui à son tour en renvoie une part vers la végétation.

L'ensemble sol-culture est schématisé (Fig. 1) à l'aide de trois plans horizontaux (Allen et Richardson, 1968; par exemple):

- le plan fictif passant par les éléments les plus élevés de la végétation,

- le plan fictif passant par les éléments les plus bas de la végétation,

- la surface du sol.

Tous les rayonnements sont donc mesurés ou estimés (dans le cadre de modèle d'interception par exemple) sur un plan horizontal. Le rayonnement absorbé par la végétation $\left(\mathrm{Rg}_{\mathrm{a}}\right)$ est déterminé (Varlet-Grancher et Bonhomme, 1974; Hodge et Kanemasu, 1977) par le bilan entre les rayonnements reçus: rayonnement incident $\left(\mathrm{Rg}_{0}\right)$ et rayonnement réfléchi par le sol $\left(\mathrm{Rg}_{\mathrm{rs}}\right)$, et les rayonnements "perdus»: rayonnement réfléchi par l'ensemble sol-culture $\left(R_{r}\right)$ et rayonnement transmis au sol $\left(\mathrm{Rg}_{\mathrm{t}}\right)$.

$$
R g_{a}=R g_{0}-R g_{t}-R g_{r}+R g_{r s}
$$

Avec Suckling et al. (1975) et surtout Gallagher et Biscoe (1978), quelques travaux considèrent le rayonnement absorbé comme la différence entre le rayonnement intercepté et le rayonnement réfléchi par l'ensemble sol-culture :

$$
\mathrm{Rg}_{\mathrm{a}}^{\prime}=\mathrm{Rg}_{\mathrm{o}}-\mathrm{Rg}_{\mathrm{t}}-\mathrm{Rg}_{\mathrm{r}}
$$

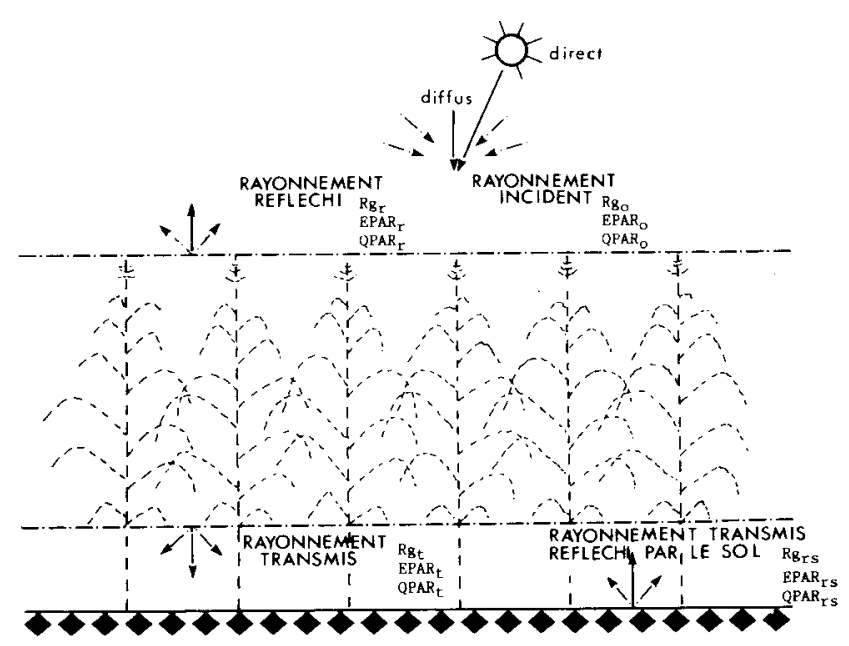

Fig. 1. Schéma montrant les différentes composantes du bilan radiatif solaire d'un couvert végétal. 
En fait, de nombreux auteurs mesurent ou estiment seulement le rayonnement intercepté $\left(\mathrm{Rg}_{\mathrm{i}}\right)$ défini comme le bilan entre le rayonnement incident et le rayonnement tranmis au sol :

$$
\mathrm{Rg}_{\mathrm{i}}=\mathrm{Rg}_{\mathrm{o}}-\mathrm{Rg}_{\mathrm{t}}
$$

Le bilan radiatif correspondant à l'équation 1 est le seul qui soit correct et doit être recommandé (Asrar et al., 1984; Gallo et Daughtry, 1986).

Pour le rayonnement utile à la photosynthèse nous pouvons écrire (cf. Tableau I):

- Rayonnement absorbé

$$
\begin{aligned}
& \text { EPAR }_{\mathrm{a}}=\mathrm{EPAR}_{\mathrm{o}}-\mathrm{EPAR}_{\mathrm{t}}-\mathrm{EPAR}_{\mathrm{r}}+\mathrm{EPAR}_{\mathrm{rs}} \\
& \mathrm{QPAR}_{\mathrm{a}}=\mathrm{QPAR}_{\mathrm{o}}-\mathrm{QPAR}_{\mathrm{t}}-\mathrm{QPAR}_{\mathrm{r}}+\mathrm{QPAR}_{\mathrm{rs}} \\
& - \text { Rayonnement intercepté } \\
& \mathrm{EPAR}_{\mathrm{i}}=\mathrm{EPAR}_{\mathrm{o}}-\mathrm{EPAR}_{\mathrm{t}} \\
& \mathrm{QPAR}_{\mathrm{i}}=\mathrm{QPAR}_{\mathrm{o}}-\mathrm{QPAR}_{\mathrm{t}}
\end{aligned}
$$

\section{Efficience de l'absorption ou de l'interception d'un couvert végétal}

Le rapport du rayonnement absorbé ou intercepté au rayonnement incident définit l'efficience du couvert végétal pour absorber ou intercepter le rayonnement solaire :

$$
\begin{aligned}
& \varepsilon_{a}=R_{a} / R_{\circ} \\
& \varepsilon_{a}^{\prime}=R g_{a}^{\prime} / R g_{\circ} \\
& \text { ou }
\end{aligned}
$$$$
\varepsilon_{\mathrm{i}}=R g_{\mathrm{i}} / \mathrm{Rg}_{\mathrm{o}}
$$

\begin{tabular}{|c|c|c|c|}
\hline & \multirow[t]{2}{*}{$\begin{array}{l}\text { Rayonnement global } \\
\qquad\left(R_{g}\right)\end{array}$} & \multicolumn{2}{|c|}{$\begin{array}{l}\text { Rayonnement utile à la photosynthèse } \\
\qquad(P A R)\end{array}$} \\
\hline & & $\begin{array}{c}\text { Eclairement énergétique } \\
\text { EPAR }\end{array}$ & $\begin{array}{l}\text { Eclairement quantique } \\
\text { QPAR }\end{array}$ \\
\hline $\begin{array}{l}\text { Rayonnement incident } \\
\text { Rayonnement transmis }\end{array}$ & $\mathrm{Rg}_{\mathrm{o}}$ & EPAR $_{0}$ & $\mathrm{QPAR}_{0}$ \\
\hline au sol par la végétation & $\mathrm{Rg}_{\mathrm{t}}$ & EPAR $_{\mathrm{t}}$ & QPAR $_{t}$ \\
\hline $\begin{array}{l}\text { Rayonnement réfléchi par } \\
\text { l'ensemble sol-culture }\end{array}$ & $\mathrm{Rg}_{\mathrm{r}}$ & EPAR $_{r}$ & QPAR $_{r}$ \\
\hline $\begin{array}{l}\text { Rayonnement réfléchi } \\
\text { par le sol }\end{array}$ & $\mathrm{Rg}_{\mathrm{rs}}$ & $\mathrm{EPAR}_{\mathrm{rS}}$ & $\mathrm{QPAR}_{\mathrm{rs}}$ \\
\hline $\begin{array}{l}\text { Rayonnement absorbé } \\
\text { par le couvert végétal }\end{array}$ & $\mathrm{Rg}_{\mathrm{a}}=\mathrm{Rg}_{\mathrm{g}_{0}}-\mathrm{Rg}_{\mathrm{f}}-\mathrm{Rg}_{\mathrm{t}}+\mathrm{Rg}_{\mathrm{rs}}$ & $\mathrm{EPAR}_{\mathrm{a}}=\mathrm{EPAR}_{\mathrm{o}}-\mathrm{EPAR}_{\mathrm{t}}-\mathrm{EPAR}_{\mathrm{r}}+\mathrm{EPAR}_{\mathrm{rs}}$ & $\mathrm{QPAR}_{\mathrm{a}}=\mathrm{QPAR}_{0}-\mathrm{QPAR}_{\mathrm{t}}-\mathrm{QPAR}_{\mathrm{r}}+\mathrm{QPAR}_{\mathrm{rs}}$ \\
\hline $\begin{array}{l}\text { Rayonnement absorbé par le } \\
\text { couvert végétal d'après } \\
\text { Gallagher et Biscoe (1978) }\end{array}$ & $\mathrm{Rg}_{\mathrm{a}}{ }^{\prime}=\mathrm{Rg}_{\mathrm{o}}-\mathrm{Rg}_{\mathrm{r}}-\mathrm{Rg}_{\mathrm{g}}$ & EPAR $_{a}{ }^{\prime}=$ EPAR $_{0}-$ EPAR $_{t}-$ EPAR $_{r}$ & $\mathrm{QPAR}_{\mathrm{a}}^{\prime}=\mathrm{QPAR}_{0}-\mathrm{QPAR}_{\mathrm{t}}-\mathrm{QPAR}_{\mathrm{r}}$ \\
\hline $\begin{array}{l}\text { Rayonnement intercepté par } \\
\text { le couvert végétal }\end{array}$ & $R g_{i}=R g_{0}-R g_{t}$ & $\mathrm{EPAR}_{\mathrm{j}}=\mathrm{EPAR}_{0}-\mathrm{EPAR}_{\mathrm{t}}$ & $\mathrm{QPAR}_{\mathrm{i}}=\mathrm{QPAR}_{\mathrm{o}}-\mathrm{QPAR}_{\mathrm{t}}$ \\
\hline $\begin{array}{l}\text { Coefficient de transmission } \\
\text { (transmittance) du couvert } \\
\text { végétal }\end{array}$ & $T=R g_{t} / R g_{0}$ & $T_{E}=E P A R_{t} / E P R_{0}$ & $\mathrm{~T}_{\mathrm{Q}}=\mathrm{QPAR}_{\mathrm{t}} / \mathrm{QPAR}_{\mathrm{o}}$ \\
\hline $\begin{array}{l}\text { Coefficient de réflexion } \\
\text { (réflectance) de l'ensemble } \\
\text { sol-culture }\end{array}$ & $R=R g_{r} / R g_{0}$ & $R_{E}=E P A R_{r} / E P A R_{t}$ & $\mathrm{R}_{\mathrm{Q}}=\mathrm{QPAR}_{\mathrm{f}} / \mathrm{QPAR}_{\mathrm{o}}$ \\
\hline $\begin{array}{l}\text { Coefficient de réflexion } \\
\text { (réflectance) du sol sous } \\
\text { la culture }\end{array}$ & $R_{s}=R g_{r s} / R g_{t}$ & $R_{S E}=E P A R_{T S} / E P A R_{0}$ & $R_{s Q}=Q_{P A R_{r s}} / Q_{P A R_{t}}$ \\
\hline $\begin{array}{l}\text { Efficience de l'absorption } \\
\text { du rayonnement solaire }\end{array}$ & $\varepsilon=1-R-T+R_{s} \times T$ & $\varepsilon_{\mathrm{a} E}=1-R_{E}-T_{E}+R_{S E} \times T_{E}$ & $\varepsilon_{\mathrm{aQ}}=1-\mathrm{R}_{\mathrm{Q}}-\mathrm{T}_{\mathrm{Q}}+\mathrm{R}_{\mathrm{sQ}} \times \mathrm{T}_{\mathrm{Q}}$ \\
\hline $\begin{array}{l}\text { Efficience de l'absorption du } \\
\text { rayonnement solaire d'après } \\
\text { Gallagher et Biscoe (1978) }\end{array}$ & $\varepsilon_{a}^{\prime}=1-R-T$ & $\varepsilon_{\mathrm{aE}}^{\prime}=1-R_{\mathrm{E}}-\mathrm{T}_{\mathrm{E}}$ & $\varepsilon_{a Q}^{\prime}=1-R_{Q}-T_{Q}$ \\
\hline $\begin{array}{l}\text { Efficience de l'interception } \\
\text { du rayonnement solaire }\end{array}$ & $\varepsilon_{i}=1-T$ & $\varepsilon_{\mathrm{iE}}=1-T_{\mathrm{E}}$ & $\varepsilon_{i Q}=1-T_{Q}$ \\
\hline
\end{tabular}

On peut aussi définir les propriétés optiques du système sol-culture :

- le coefficient de transmission (ou transmittance) de la végétation : $T=R g_{t} / R g_{0}$

- le coefficient de réflexion (ou réflectance) du couvert végétal $: R=R_{r} / R g_{\circ}$

Tableau I. Principaux symboles et relations pouvant être utilisés dans les études du bilan radiatif d'un couvert végétal. 
- le coefficient de réflexion (ou réflectance) du sol sous la culture : $R_{s}=R g_{r s} / R_{t}$

Les efficiences peuvent s'exprimer en fonction de ces coefficients :

- pour le rayonnement absorbé :

$$
\varepsilon_{\mathrm{a}}=1-T-R+R_{\mathrm{s}} \quad \text { (11) d'après }
$$

ou

$$
\varepsilon_{\mathrm{a}}^{\prime}=1-\mathrm{T}-\mathrm{R} \quad \text { (12) d'après }
$$

- pour le rayonnement intercepté :

$$
\varepsilon_{i}=1-T \quad \text { (13) d'après }
$$

Des expressions analogues peuvent être écrites pour le rayonnement utile à la photosynthèse, par exemple pour la transmittance:

$T_{E}=E P A R_{t} / E P A R_{0}$ pour l'éclairement énergétique,

et

$T_{Q}=Q_{P A R_{t}} /$ QPAR $_{0}$ pour l'éclairement photonique.

Ces différentes caractérisations sont données au Tableau I.

\section{Mesure des différentes composantes du bilan radiatif}

\section{Les capteurs}

Les principaux types d'instruments destinés à mesurer le rayonnement solaire ont été décrits par Kubin (1971) puis par Fritschen et Gay (1979). Le travail plus récent de Bingham et Long (1985) donne une liste importante, mais non exhaustive, de capteurs commerciaux et quelques-unes de leurs caractéristiques. Une étude comparative de tous ces instruments resterait donc à faire. Dans ce qui suit nous voulons seulement rappeler le principe des capteurs les plus couramment utilisés pour la mesure des caractérisations du rayonnement solaire définies précédemment $\left(R_{g}, E P A R, Q P A R\right)$ ainsi que leurs principales limites d'utilisation. Ces instruments présentent tous une surface réceptrice plane avec un angle d'ouverture de $2 \pi$ stéradians et sont en principe corrigés (plus ou moins bien) en cosinus pour les rayonnements non perpendiculaires.

\section{Mesure du rayonnement solaire total $\left(R_{g}\right)$}

Tous les instruments destinés à mesurer le rayonnement solaire total sont des pyranomètres (quelquefois appelés solarimètres). Les appareils les plus anciens et les plus courants sont des radiomètres thermo-électriques (absorption du rayonnement et transformation en signal électrique par une thermopile), leur réponse est indépendante de la longueur d'onde et ils peuvent donc être utilisés dans toutes conditions (dans la culture, sous-abri, avec des sources de lumière artificielle). Les pyranomètres de ce type qui sont les plus utilisés en mesure de "routine" sont des instruments ayant une surface réceptrice de quelques centimètres carrés (capteur «ponctuel») recouverte par 1 ou 2 coupelles hémisphériques en verre; les constructeurs les plus anciens et les plus importants sont certainement Eppley et Kipp et Zonen (Tableau II). Ces instruments sont maintenant couramment intégrés dans les différents réseaux météorologiques pour déterminer le rayonnement global incident et ses composantes directe et diffuse. Ils sont considérés comme des instruments standard de référence.

Des capteurs linéaires ont aussi été développés (Szeicz et al., 1964; Combres et al., 1970) pour mesurer le rayonnement total au sein d'un peuplement végétal. Ils diffèrent des précédents par leur surface réceptrice plus grande et de forme rectangulaire ( 1 à $2 \mathrm{~cm}$ sur 20 à $100 \mathrm{~cm}$ ) placée dans un tube de verre; leur commercialisation est maintenant assez courante.

Plus récemment, des capteurs à détecteur quantique (cellules photovoltaïques au silicium) ont été développés pour mesurer le rayonnement solaire global incident et sont également qualifiés de pyranomètres. La réponse de ces capteurs dépend de la longueur d'onde du rayonnement dans une gamme (généralement 400-1 $100 \mathrm{~nm}$ ) qui ne recouvre pas complètement celle du rayonnement total (300-3 000 nm). Ces instruments sont étalonnés par comparaison avec un pyranomètre thermo-électrique pour un rayonnement solaire global moyen pour lequel les variations de composition spectrale peuvent être considérées comme faibles. Aussi ces capteurs ne doivent pas être utilisés pour les situations où la qualité de la lumière peut être différente de celle de l'étalonnage et notamment à l'intérieur d'un couvert végétal ou avec des sources artificielles.

Mesure du rayonnement utile à la photosynthèse (PAR)

La sensibilité spectrale des instruments qui mesurent le PAR est particulièrement importante puisque leur réponse doit couvrir une gamme précise de radiations : $400-700 \mathrm{~nm}$ et être indépendante ou non de la longueur d'onde selon que l'on mesure l'éclairement énergétique EPAR ou quantique QPAR.

a) Eclairement énergétique : EPAR. L'éclairement énergétique utile à la photosynthèse EPAR est généralement obtenu par différence entre les mesures effectuées à l'aide de deux pyranomètres thermo-électriques (ponctuels ou linéai- 
Tableau II. Principaux capteurs commerciaux permettant de mesurer le rayonnement solaire.

\begin{tabular}{|c|c|c|c|}
\hline Type de & Type de & Rayonnement solaire total & Rayonnement utile à la photosynthèse (PAR) \\
\hline capteur & rayonnement & $\begin{array}{c}\left(r_{g}\right) \\
\text { Instrument }=\text { Pyranomètre }\end{array}$ & $\begin{array}{cc}\text { Eclairement énergétique } & \text { Eclairement quantique } \\
\text { (EPAR) } & \text { (QPAR) }\end{array}$ \\
\hline
\end{tabular}

\section{Capteur Ponctual}

Détecteur $=$ thermopile

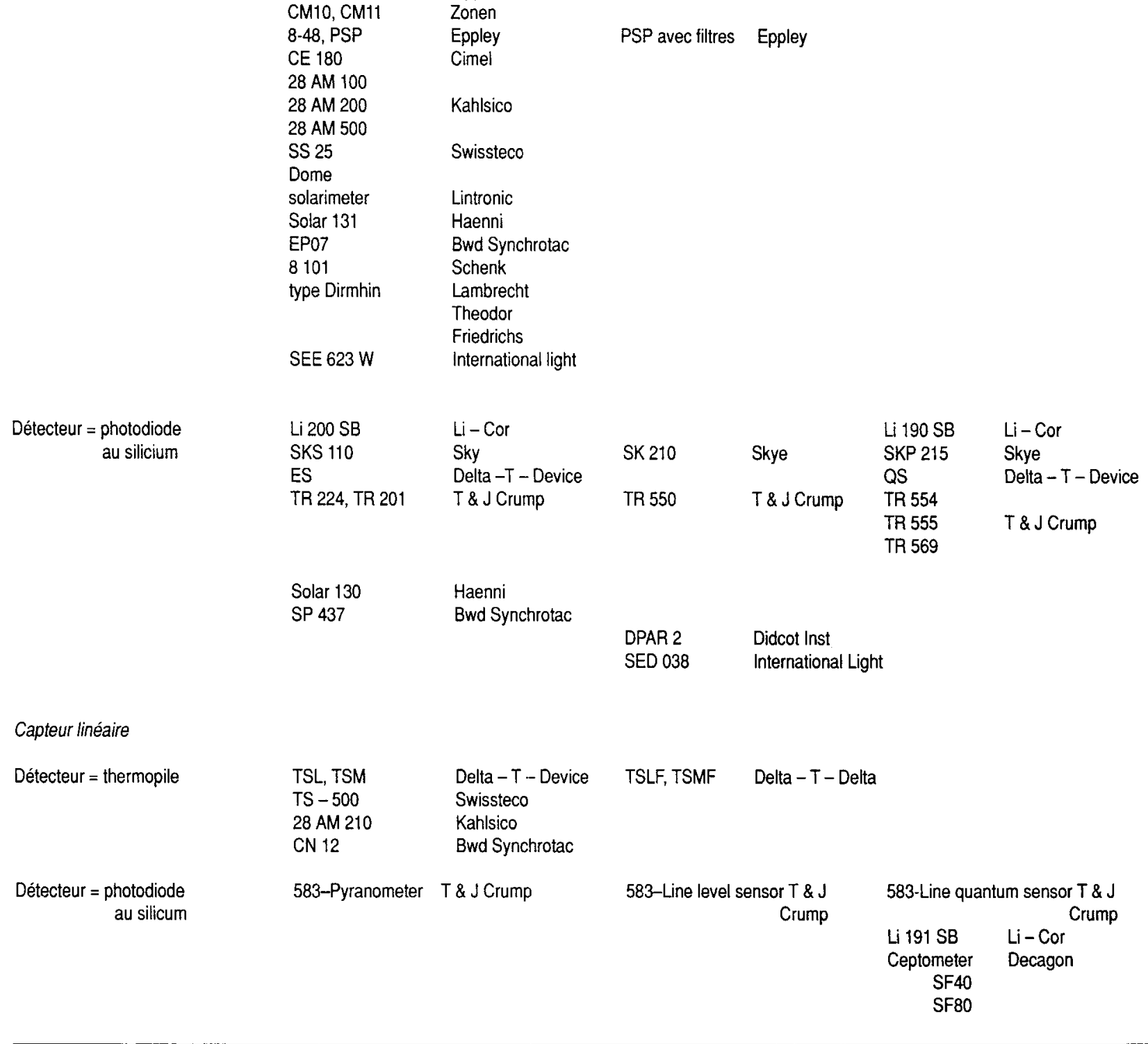

Adresse des firmes commercialisant les capteurs indiqués dans ce tableau :

Bwd Precision Instruments : Bwd Synchrotac : 5 Dunlop Road Mulgrave, PO Box 298 Mulgrave North Victoria, 3171 Australie; - Cimel 5 rue Cité de Phalsbourg, 75011 Paris France; - T \& J Crump Scientific Instruments, Carlone House, Church Road Ramsden Bellhouse Billericay, Essex CM 11 1RR, Grande-Bretagne; - Delta - T - Devices, 128 Low road Burwell, Cambridge, CB 5 OEJ Grande-Bretagne. - Didcot Instrument Company Lim. Station road Abingdon, Oxon OX 14 3LD, Grande-Bretagne; -The Eppley Laboratory Inc., 12 Sheffield ave, Newport, RI 02840 USA; - Haenni et Cie Ag., CH 3303 Jegenstorf, Suisse; - Haenni Inst. SA, 19-29 rue Jean Lolive, 93170 Bagnolet France; - International Light Inc., Dexter Industrial Green, Newburypot MA 01950 USA; - Kahlsico, Kahl Scientific Inst. Corp. PO, Box 1166 El Cajon San Diego California 92022 USA; - Kipp et Zonen PO Box 507 Mercuriusweg, 1 Delft, Pays Bas (Nombreux correspondants en France); - Lambretch Gmbh, Friedlander Weg 65-67 PO Box 2654 D 3400 Goettingen RFA, Représentant en France : Prometron; - Prometron, 108 bis rue Championnet, 75018 Paris France; - Li - Cor, Inc/LI - Cor, Ltd Box 4425 Lincoln Nebraska, 68504 USA; Représentant en France: Cunow; - Cunow 11 av. de Laades, 95800 Cergy St Christophe France; - Lintronic Lim. 54-58 Bartholomew Close London EC 1A 7HB Grande-Bretagne; - Schenk Ges. m.b. H. Wien et Co, K.G. A.1212 Wien, Autriche; Représentant en France: Prometron; - Théodor Friedrichs, POB 1105 Borgfeld 6, D 2000 Schenefed RFA; - Skye Instruments Ltd Unit 5 Ddole Industrial Estate, Liandrindod Wells, Powys LDI 6DF Grande-Bretagne; - Swissteco Instruments Stegweg, Eichenwies CH-9463 Oberriet SG, Suisse; - Decagon Device Inc. P.O. Box 835, Pullman WA 99163 USA.

"Ce tableau n'est pas exhaustif, la citation d'une firme ne constitue ni une recommandation ni une garantie. L'ordre dans lequel sont donnés les differrents instruments n'a pas de signification particulière. 
res) dont l'un est muni d'un filtre (KODAK WRATEN 85A ou Schott RG695 par exemple) qui transmet seulement les radiations infra-rouges (longueurs d'onde supérieures à $700 \mathrm{~nm}$ ).

L'utilisation de filtre "passe-bas" qui transmet les radiations visibles éviterait l'installation de deux capteurs et le cumul des erreurs qui en résulte, mais ce type de filtre (passe-bande athermique SCHOTT KG3 ou HOYA HA-20) n'est pas actuellement adaptable sur des capteurs linéaires.

Les caractéristiques des filtres "passe-haut" ne permettent pas d'éliminer les radiations inférieures à $400 \mathrm{~nm}$ (environ $5 \%$ du rayonnement global) : l'éclairement énergétique EPAR est donc surestimé. De plus, l'absorption d'une quantité importante d'énergie $(50 \%$ au moins du rayonnement incident) peut modifier la réponse du capteur lui-même par échauffement du récepteur notamment (Suraqui et al., 1977). La maintenance de ces filtres sur de longues périodes paraît difficile (dégradation de la gélatine qui les compose) et certains constructeurs recommandent de ne pas utiliser les capteurs filtrés sous fort rayonnement !!!

Depuis quelques années, il existe des cellules photo-électriques munies de filtres (capteurs CRUMP et SKYE notamment) qui ont une réponse spectrale satisfaisante permettant de mesurer correctement EPAR. La firme CRUMP commercialise un instrument composé de plusieurs cellules montées sur un support linéaire et placées dans un tube avec diffuseur afin de mesurer EPAR transmis sous un couvert végétal.

b) Eclairement quantique : QPAR. L'éclairement quantique QPAR est mesuré à l'aide de cellules photo-électriques (cellules au silicium) dont la réponse dépend de la longueur d'onde de manière à obtenir un signal proportionnel au nombre de photons reçus. Les capteurs ponctuels de ce type sont maintenant très courants alors que les capteurs linéaires sont encore peu développés: LI-COR (une seule cellule sur l'ensemble du capteur), DECAGON (une centaine de cellules placées les unes contre les autres) et CRUMP (quelque cellules espacées de plusieurs centimètres et montées sous un diffuseur commun).

\section{Autre type de mesure}

Bien que l'éclairement lumineux ne soit pas représentatif du rayonnement utile à la photosynthèse, les capteurs photométriques (luxmètres...) sont encore parfois utilisés (Hughes et al., 1981; Foale et al., 1984).
Les méthodes de mesure ou d'estimation des différentes composantes du bilan radiatif

Le bilan radiatif du couvert végétal est obtenu, quelle que soit la gamme spectrale considérée, à partir (Fig. 1):

- d'un capteur horizontal situé au-dessus de la culture considérée ou à proximité: rayonnement incident $\left(\mathrm{Rg}_{\mathrm{o}}\right)$,

- d'un capteur horizontal en position inverse (face vers la végétation) situé généralement à $1 \mathrm{~m}$ au-dessus des feuilles les plus hautes (plan supérieur fictif) : rayonnement réfléchi par l'ensemble sol-culture $\left(\mathrm{Rg}_{\mathrm{r}}\right)$,

- d'un capteur (linéaire ou plusieurs capteurs ponctuels ou autre système) placé horizontalement au niveau du sol : rayonnement transmis $(\mathrm{Rg})$,

- d'un capteur horizontal en position inverse (face vers le sol) situé au niveau des premières feuilles (plan inférieur fictif) : rayonnement réfléchi par le sol $\left(\mathrm{Rg}_{\mathrm{rs}}\right)$.

\section{Rayonnements incidents}

Les rayonnements incidents peuvent être mesurés par les capteurs décrits précédemment, placés horizontalement en un endroit totalement dégagé. La valeur journalière des rayonnements utiles à la photosynthèse incidents $E{ }{ }^{2} R_{0}$ et $\mathrm{QPAR}_{\mathrm{o}}$ peut aussi être estimée à partir du rayonnement journalier total $\mathrm{Rg}_{0}$ obtenu par un pyranomètre selon les relations:

$$
\mathrm{EPAR}_{0} / \mathrm{Rg}_{\mathrm{o}}=0,48 \pm 0,02\left(\mathrm{EPAR}_{\mathrm{o}} \text { et } \mathrm{Rg}_{\mathrm{o}}\right. \text { en MJ) }
$$

(Varlet-Grancher et al., 1982)

QPAR $_{0} / \mathrm{Rg}_{\circ}=2,02 \pm 0,01 \mathrm{Mol}^{\mathrm{MJ}} \mathrm{M}^{-1}$

(Varlet-Grancher et al., 1981)

D'autres relations établies par différents auteurs et pour différents pas de temps sont très proches de celles-ci (cf. Tableau III).

Mesures des rayonnements réfléchis par l'ensemble sol-culture $R g_{r}$ et par le sol $R g_{r s}$

L'utilisation des capteurs en position inverse pour déterminer le rayonnement réfléchi entraîne différentes possibilités d'erreurs (Flowers et Helfert, 1966; Stanhill et al., 1971; Norris, 1974) et nécessite quelques précautions notamment pour éviter la pénétration de rayonnements directs aux faibles hauteurs du soleil : positionnement du capteur à une faible distance au-dessus de la surface considérée et/ou système de "cache" pare-soleil (Brown et al., 1970).

Cependant, le rayonnement réfléchi mesuré doit provenir d'une surface assez importante pour prendre en compte les hétérogénéités horizontales dues, notamment pour l'ensemble sol- 
Tableau III. Rayonnement incident: estimation des éclairements énergétiques et quantiques utiles à la photosynthèse $\left(\mathrm{EPAR}_{0}, \mathrm{QPAR}_{0}\right.$ ) à partir du rayonnement global $\mathrm{Rg}_{0}$.

Type Intégration

$E P A R / R g_{0}$

$$
\begin{aligned}
& 0,50 \pm 0,03 \\
& 0,45-0,50 \\
& 0,46 \\
& 0,46 \\
& 0,492 \pm 0,051 \\
& 0,51 \pm 0,01 \\
& 0,63 \pm 0,02 \\
& 0,47-0,58 \\
& 0,471 \pm 0,069 \\
& 0,48 \pm 0,02 \\
& 0,47 \\
& 0,457 \pm 0,029 \\
& \text { QPAR }_{0} / \text { EPAR }_{0} \\
& \text { 4,54 } \mu \text { Moles W-1 } \\
& \mathrm{QPAR}_{0} / \mathrm{Rg} \text { 。 } \\
& 2,1-2,3 \mu \text { MolW-1 } \\
& \text { 2,1 - 2,6 MolMJ-1 } \\
& 2,17 \\
& 2,55 \\
& 2,02 \pm 0,01 \\
& 2,05 \pm 0,05 \\
& 2,05 \pm 0,06 \\
& 2,06
\end{aligned}
$$

\author{
Val. instantanées \\ Val. instantanées \\ Val. instantanées \\ Val. instantanées \\ Val. 1/2 horaires \\ - ciel clair \\ - ciel couvert \\ Val. journalières \\ Val. journalières \\ Val. journalières \\ Val. journalières \\ Val. journalières
}

Val. instantanées

Val. instantanées
Val. journalières
Val. journalières
Val. journalières
Val. journalières
Val. journalières
Val. journalières
Val. journalières
Référence

\author{
Szeicz (1974) \\ Varlet-Grancher (1975) \\ Pereira et al. (1972) \\ Weiss et Norman (1985) \\ Stanhill et Fuchs (1977) \\ Stigter et Musabilha (1982) \\ Britton et Dodd (1976) \\ Stanhill et Fuchs (1977) \\ Varlet-Grancher et al. (1982) \\ Blackburn et Proctor (1983) \\ Nagaraja Rao (1984)
}

McCartney (1978)

Varlet-Grancher (1975)
Britton et Dodd (1976)
Hodge et Kanemasu (1977)
Hodge et al. (1979)
Varlet-Grancher et al. (1981)
Howell et al. (1983)
Meek et al. (1984)
Sivakumar (1984) in :
Sivakumar et Virmani (1984) culture, aux effets de rang. Cela implique soit de placer le capteur suffisamment éloigné du sommet de la végétation (avec le risque d'une pénétration de rayons directs au lever et au coucher du soleil), soit d'utiliser un système de déplacement du capteur au-dessus du couvert végétal (Berglund et Mace, 1972). Mais très généralement, les mesures sont effectuées en plaçant le capteur en position fixe entre 1 et $3 \mathrm{~m}$ au-dessus de la surface considérée (Stanhill et al., 1968; Kalma et Badham, 1972; Varlet-Grancher, 1974; Fuchs et al., 1976 par exemple). Pour un couvert végétal, le capteur est mis à la verticale du milieu d'un rang au centre d'une parcelle suffisamment importante (à $1 \mathrm{~m}, 90 \%$ de l'énergie mesurée provient d'une surface d'environ $30 \mathrm{~m}^{2}$ d'après Slatyer et Mcllroy, 1961).

Dans de nombreux cas (cultures en phase d'installation, cultures basses, espèces stolonifères, etc.), le rayonnement réfléchi par le sol est difficile à mesurer et ne peut être obtenu qu'à partir du coefficient de réflexion du sol nu « $\mathrm{a}_{\mathrm{s}}$ " et du rayonnement transmis $R_{g_{t}}\left(R_{g_{r s}}=a_{s} \times R g_{t}\right)$.

II est possible d'estimer la valeur de $a_{s}$ à partir du rayonnement incident et du rayonnement réfléchi par une parcelle de sol nu voisine de la parcelle expérimentale, selon un pas de temps choisi (horaire, journalier, etc.) et de l'utiliser dans le bilan radiatif du couvert végétal (Gallo et Daughtry, 1986). Mais on considère le plus souvent une seule valeur moyenne de $a_{s}$ correspondant à celle obtenue lorsque la couche superficielle du sol est saturée en humidité. Comme $a_{s}$ augmente fortement avec le dessèchement du sol, cette méthode sous-estime systématiquement $\mathrm{Rg}_{\mathrm{rs}}$.

Mesure du rayonnement transmis par la végétation $R g_{t}$

La variabilité de l'énergie transmise au sol peut être très importante selon l'état de développement de la végétation (mise en place de la cultu- 
re, phase reproductive, sénescence, etc.), l'hétérogénéité du couvert végétal (semis en rangs notamment), et le type de temps (ciel couvert, ciel clair : présence de "taches" de soleil).

L'étude de la distribution des taches de soleil et de l'éclairement à l'intérieur d'un couvert végétal est très importante pour caractériser le microclimat lumineux dans la végétation (Chartier, 1966; Bonhomme, 1970; Sinclair et Lemon, 1974). Cependant, dans le cadre de l'utilisation du rayonnement intercepté pour analyser la production de matière sèche d'une culture, il faut établir la valeur moyenne de l'éclairement reçu par l'unité de surface de sol.

a) Les méthodes. Les différentes méthodes qui ont été développées (cf. revue de Anderson, 1971) peuvent être regroupées selon deux grands types:

- les méthodes indirectes qui sont basées sur la détermination de fréquences des trouées et/ou des taches de soleil dans le couvert végétal (photographies hémisphériques, "point quadrat»; taux de recouvrement),

- les méthodes directes qui correspondent à des mesures radiatives (capteurs ponctuels disposés en réseau, déplacement d'un capteur ponctuel dans la végétation, capteur linéaire) qui sont les seules que nous présenterons.

Les «réseaux»

L'utilisation de plusieurs capteurs répartis sur un même niveau dans le couvert végétal (disposition en «réseau») permet d'obtenir une valeur moyenne (montage en série ou moyenne des valeurs individuelles). Cette méthode, utilisée par différents auteurs (Williams et al., 1968; Hatfield et Carlson, 1978; Khurana et McLaren, 1982), nécessite un grand nombre de capteurs pour obtenir une précision satisfaisante sur les valeurs moyennes instantanées (Reifsnyder et al., 1971). Toutefois, en intégration journalière, ce nombre (10 à 20 environ) est beaucoup plus faible et compatible avec l'expérimentation.

La disposition des capteurs en réseau est assez peu pratique pour des cultures basses ou denses et elle a été le plus souvent utilisée pour étudier l'hétérogénéité du rayonnement dans la végétation.

Pour rendre les mesures plus faciles à effectuer, les capteurs peuvent être montés à égale distance sur une réglette rigide qui peut être alors introduite dans la végétation avec moins de perturbations (Williams et Austin, 1977; Foale et al., 1984).

\section{Les systèmes mobiles}

Pour des cultures suffisamment hautes, un assez grand nombre d'auteurs ont mis au point des sys- tèmes permettant de déplacer un capteur ponctuel à l'intérieur d'un guide (Laisk, 1969; Matthews et Saffell, 1987) ou sur un chariot (Baker et Musgrave, 1964; Kornher et Rodskjer, 1967; Chartier et al., 1971; Vidovic, 1975; Gardiner et al., 1979; Sinoquet, 1988, par exemple).

Le signal est intégré sur la longueur parcourue (de un à quelques mètres) pour obtenir une valeur moyenne. La vitesse d'avancement doit :enir compte du temps de réponse du capteur pour enregistrer les fluctuations rapides de l'éclairement sur le trajet, et le temps de parcours doit être suffisamment court pour éviter une variation trop importante du rayonnement incident. L'intégration peut aussi être effectuée de manière discrète à partir des réponses obtenues en différents points du parcours et traitées séparément. Lorsque le couvert végétal est hétérogène (effet "rang") les caractéristiques du dispositif doivent permettre d'obtenir une distribution de ces points de mesure aussi uniforme que possible (Sinoquet, 1988). Quelques-uns de ces problèmes ont plus particulièrement été discutés par Sinclair et al. (1974). Cette méthode est toujours délicate à mettre en œuvre et demande une surveillance assez importante du matériel; enfin, son utilisation est pratiquement impossible dans le cas de cultures basses ou denses.

Les quelques travaux qui comparent réseaux et systèmes mobiles (Brown, 1973; Suckling et al., 1975; Vidovic, 1975; Pech, 1986) montrent que le déplacement d'un capteur permet d'obtenir la meilleure précision (coefficient de variation plus faible). Mais dans ces comparaisons, le nombre de capteurs en réseau était toujours, il est vrai, assez faible (inférieur à 10).

A noter le montage "mixte» de Sivakumar et Virmani (1984) qui est composé de 4 capteurs ponctuels se déplaçant sur des guides horizontaux longs de 1,5 m et équidistants entre eux de $0,4 \mathrm{~m}$.

\section{Les capteurs linéaires}

La mise au point de capteurs de plus grande dimension et de forme allongée: pyranomètres linéaires (Szeicz et al., 1964; Combres et al., 1970; Luxmoore et al., 1971) puis capteurs quantiques linéaires, a permis de trouver un compromis satisfaisant entre les conditions d'une bonne intégration du rayonnement et celles d'une mise en place facile dans tous les types de végétation.

L'utilisation de ces instruments est devenue maintenant très courante; selon leur dimension (quelques $\mathrm{cm}$ de largeur sur 20 à $100 \mathrm{~cm}$ de longueur) et l'hétérogénéité du couvert végétal (écartement des rangs surtout), les mesures sont faites avec un ou plusieurs capteurs montés en série. II ne semble pas que ces différents sys- 
tèmes (réseaux, capteurs mobiles, capteurs linéaires) aient été systématiquement testés les uns par rapport aux autres pour établir le bilan radiatif du couvert végétal; seuls quelques travaux comparent les méthodes deux à deux et toujours dans le cagdre d'une analyse du rayonnement transmis au sol.

b) Les conditions d'installation et de mise en œuvire Lorsque la structure du couvert végétal étudié est homogène, la mise en œuvre de ces méthodes est facile. II suffit de placer les instruments utilisés au milieu d'une parcelle assez grande pour permettre une bonne intégration du rayonnement reçu par le ou les capteurs et éviter un effet de bord (rayonnement provenant de l'extérieur de la parcelle considérée). Cependant les mesures peuvent être difficiles à réaliser lorsque la taille des capteurs est importante par rapport à la hauteur de la végétation (cas de plantes rampantes par exemple).

La structure du couvert végétal est très souvent hétérogène. L'apparition d'organes floraux et la sénescence des feuilles peuvent entraîner la formation de «strates» à l'intérieur de la végétation; les capteurs doivent donc être placés en fonction de la couche des feuilles actives (Chartier et al., 1983; Yates et Steven 1987). Beaucoup de plantes cultivées sont disposées en rang et les systèmes de capteurs mobiles ou linéaires sont presque toujours placés perpendiculairement à la direction de ces rangs. Mais le rayonnement tranmis ainsi mesuré dépend de la longueur du capteur et de la largeur entre rangs (prise en compte d'une proportion variable du rang). Pour une culture de maïs, Gallo et Daughtry (1986) montrent que le meilleur dispositif consiste à centrer le capteur (ici un LI-COR) sur le rang et à ramener sa longueur (un mètre) à celle de l'interrang (ici $0,76 \mathrm{~m}$ ) à l'aide de caches. Ils ont aussi montré que l'utilisation de plusieurs capteurs (ramenés à $0,76 \mathrm{~m}$ placés parallèlement au rang et à égale distance entre eux $(0,125 \mathrm{~m})$ semblait sous-estimer le rayonnement transmis.

D'autres auteurs (Khurana et McLaren, 1982; Gosse et al., 1982; Charles-Edwards et Lawn, 1984) ont adopté un dispositif de capteurs parallèles au rang mais en ne mesurant que le rayonnement transmis sous le rang (pas de capteur dans l'interrang). Cette mesure est alors corrigée par un taux de recouvrement qui correspond le plus souvent à la projection orthogonale au sol de la surface moyenne occupée par le rang. Charles-Edwards et Lawn (1984) montrent que des mesures ainsi effectuées autour du midi solaire permettent d'avoir une bonne estimation de l'interception journalière moyenne d'une culture en rang.
Dans tous ces dispositifs on suppose toujours que les capteurs ont une réponse homogène quelle que soit l'hétérogénéité de l'éclairement de la surface réceptrice (pas d'effet de la hauteur du soleil ou de l'orientation du rang sur la réponse intrinsèque du capteur). Cette condition semble bien respectée pour les capteurs LI-COR (une seule cellule homogène) et DECAGON (enregistrement séparé du signal de chaque cellule).

\section{Etablissement du bilan radiatif}

Rayonnement intercepté et rayonnement absorbé

Le bilan radiatif complet qui permet de calculer le rayonnement absorbé (cf. équation 1) est assez rarement établi; quelques auteurs négligent le rayonnement réfléchi par le sol (cf. équation 2) mais la majorité des travaux sur l'analyse de la croissance par rapport au rayonnement solaire, considère le rayonnement intercepté (cf. équation 3).

Pour comparer ces différentes expressions nous avons utilisé les résultats obtenus par Gosse et al. (1982) sur une culture de luzerne. La Figure 2a montre l'évolution des composantes du bilan radiatif rapportées au rayonnement incident pour l'énergie utile à la photosynthèse (EPAR) au cours d'une repousse; elle illustre bien la part essentielle du rayonnement transmis dans les variations de l'interception. La Figure $2 b$ donne les relations efficience-indice foliaire pour les trois types de bilan radiatif : rayonnement absorbé $\left(\varepsilon_{\mathrm{aE}}=1-\mathrm{T}_{\mathrm{E}}-R_{E}+R_{S E} T_{E}\right.$, avec $\left.R_{\mathrm{SE}}=0,10\right)$, absorbé selon Gallagher $\left(\varepsilon_{\mathrm{aE}}^{\prime}=1-\right.$ $\left.T_{E}-R_{E}\right)$ et intercepté $\left(\varepsilon_{i E}=1-T_{E}\right)$.

Les efficiences obtenues par ces relations diffèrent peu entre elles dès que l'indice foliaire est supérieur à 1. Pour les faibles valeurs de l'IF l'expression de Gallagher $\left(\varepsilon_{\mathrm{aE}}^{\prime}\right)$ peut sous-estimer assez fortement le rayonnement absorbé $(\approx 25 \%$ pour $\mathrm{IF}=0,5)$. Cette sous-estimation dépend évidemment du coefficient de réflexion $\left(R_{\mathrm{SE}}\right) d u$ sol sous la culture et peut devenir encore plus importante (Fig. 2c) avec son dessèchement (augmentation de $\mathrm{R}_{\mathrm{SE}}$ ).

Les quantités d'énergie absorbée et interceptée calculées avec ces relations diffèrent peu sur l'ensemble de la repousse; les écarts sont inférieurs à $10 \%$. Ainsi ces trois expressions de l'efficience semblent pouvoir être utilisées indifféremment :

- lorsque la végétation est assez développée (IF>1) ou,

- pour établir le bilan radiatif sur une période assez longue, ce qui permet de minimiser la durée de la phase d'implantation. 
a

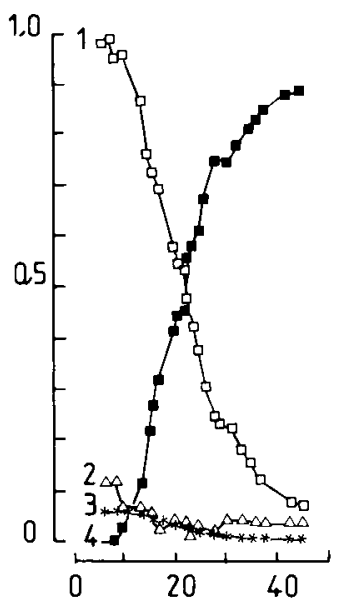

Jours après coupe b

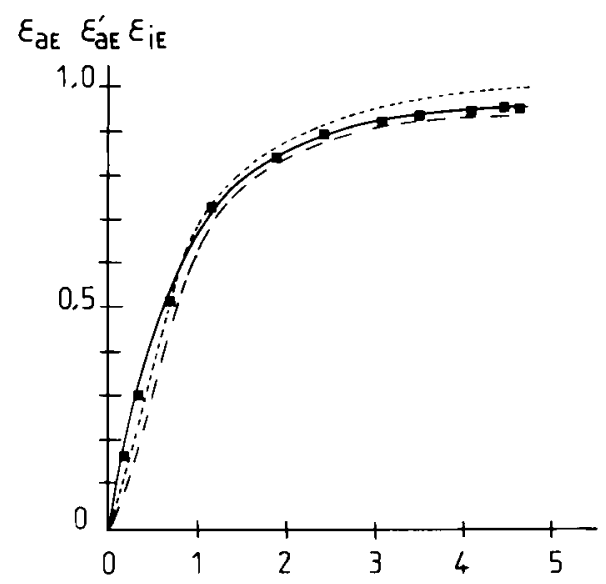

Indice foliaire

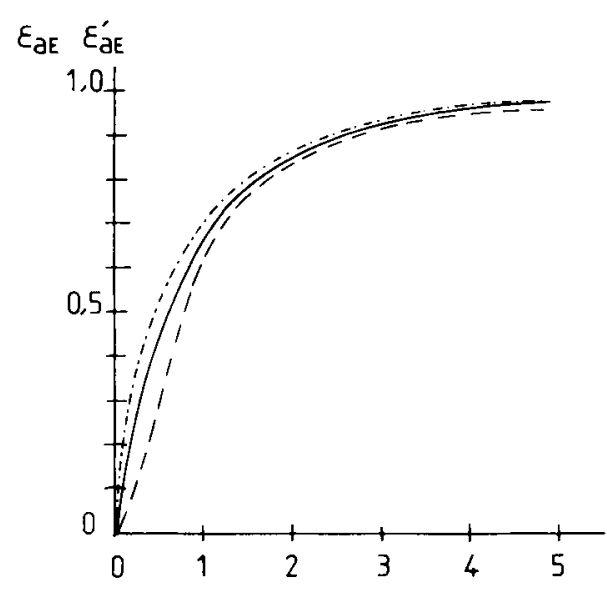

IF

Fig. 2. a) Evolution de l'efficience de l'absorption de l'énergie utile à la photosynthèse $\varepsilon_{a E}$ (valeurs journalières) et de ses composantes au cours d'une repousse de luzerne (d'après Varlet-Grancher, 1982).

- Courbe 1: Transmittance $T_{E}$ du couvert végétal - Courbe 2: Réflectance $R_{E}$ sol-culture - Courbe 3: Réflexion du sol: $R_{S E} \times T_{E}-$ Courbe 4: Efficience $\varepsilon_{\mathrm{a} E}$

b) Variations des efficiences de l'absorptions $\varepsilon_{\mathrm{aE}}, \varepsilon_{\mathrm{aE}}^{\prime}$ et de l'interception $\varepsilon_{\mathrm{iE}}$ de l'énergie utile à la photosynthèse en fonction de l'indice foliaire IF pour une repousse de luzerne (d'après Gosse et al., 1982).

$\varepsilon_{\mathrm{aE}}=1-T_{E}-R_{E}+R_{S E} \times T_{E}$ (avec $\left.R_{S E}=0,10\right) ;--\varepsilon_{a E}^{\prime}=1-T_{E}-R_{E} ;-\cdots-\varepsilon_{i E}=1-T_{E}$

c) Variations des efficiences de l'absorption $\varepsilon_{\mathrm{aE}}$ et $\varepsilon_{\mathrm{aE}}^{\prime}$ de l'énergie utile à la photosynthèse en fonction de l'indice foliaire IF pour une repousse de luzerne lorsque la réflectance du sol sous la culture passe de 0,10 à 0,20 .

$\longrightarrow \varepsilon_{\mathrm{aE}}=1-\mathrm{T}_{\mathrm{E}}-\mathrm{R}_{\mathrm{E}}+\mathrm{R}_{\mathrm{SE}} \times \mathrm{T}_{\mathrm{E}} 1\left(\mathrm{R}_{\mathrm{SE}}=0,10\right) ;-\cdots \varepsilon_{\mathrm{aE}}=1-\mathrm{T}_{\mathrm{E}}-\mathrm{R}_{\mathrm{E}}+\mathrm{R}_{\mathrm{SE}} \times \mathrm{T}_{\mathrm{E}} 2\left(R_{\mathrm{SE}}=0,20\right) ;---\varepsilon_{\mathrm{aE}}^{\prime}=1-\mathrm{T}_{\mathrm{E}}-\mathrm{R}_{\mathrm{E}}$

Pour ces conditions, la mesure du rayonnement intercepté peut donc être recommandée puisqu'elle est la plus simple à mettre en œuvre.

\section{Bilan radiatif et caractérisation du rayonnement}

Selon les techniques mises en cuvre, le bilan radiatif peut être établi par rapport :

- au rayonnement total $\left(R_{g}\right)$ ou,

- à l'éclairement énergétique utile à la photosynthèse (EPAR) ou,

- à l'éclairement quantique utile à la photosynthèse (QPAR).

Cependant la conversion du rayonnement solaire en biomasse est souvent analysée en terme de rendement énergétique (Monteith, 1972; McKinnon et al., 1978; Varlet-Grancher et al., 1982).

Dans ces conditions, les rayonnements absorbés ou interceptés doivent être exprimés en énergie utile à la photosynthèse.

Ils peuvent être obtenus directement à partir du bilan radiatif ou à partir du rayonnement incident et des efficiences de l'absorption et de l'interception:

$$
\begin{aligned}
\text { EPAR }_{\mathrm{a}} & =\mathrm{EPAR}_{\mathrm{o}} \times \varepsilon_{\mathrm{aE}} \\
\mathrm{EPAR}_{\mathrm{i}} & =\mathrm{EPAR}_{\mathrm{o}} \times \varepsilon_{\mathrm{iE}}
\end{aligned}
$$

En fait, dans de nombreux travaux, $\varepsilon_{\mathrm{aE}}$ et $\varepsilon_{\mathrm{iE}}$ sont remplacés par des efficiences établies pour les autres expressions du rayonnement solaire (énergie totale, éclairement quantique ou parfois éclairement lumineux). Cette méthode suppose donc que les valeurs de ces différentes efficiences soient peu différentes de $\varepsilon_{\mathrm{aE}}$ et $\varepsilon_{\mathrm{iE}}$.

Comme les feuilles absorbent peu les radiations du proche infra-rouge, les valeurs de l'efficience calculées pour le rayonnement total sont donc plus faibles que celles obtenues pour le rayonnement utile à la photosynthèse; les différences sont beaucoup plus importantes pour le rayonnement absorbé (Fig. 3a) que pour le rayonnement intercepté (Fig. $3 b$ ) en conditions d'alimentation hydrique non limitante. La sécheresse entraîne une modification des propriétés optiques des feuilles beaucoup plus importante dans l'infra-rouge que dans le visible, et l'on peut donc prévoir des écarts plus forts entre les rayonnements interceptés (total-PAR); la modification du port de la plante étant la même pour les deux types de rayonnement.

Avec le développement des mesures en photons, de nombreux bilans radiatifs sont maintenant exprimés en éclairement quantique utile à la photosynthèse (QPAR) et l'on considère que l'efficience ainsi obtenue $\left(\varepsilon_{\mathrm{aQ}}\right)$ est identique à celle 


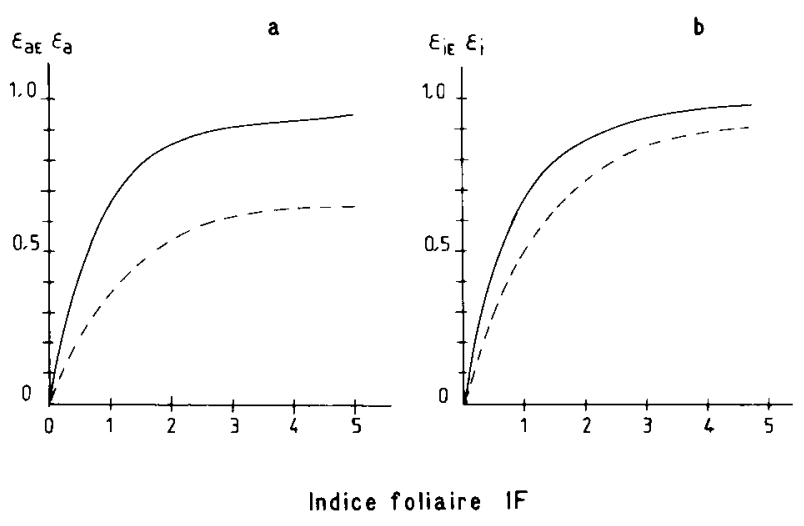

Fig 3. a) Variations des efficiences de l'absorption de l'énergie utile à la photosynthèse $\varepsilon_{\mathrm{aE}}$ et du rayonnement total $\varepsilon_{\mathrm{a}}$ en fonction de l'indice foliaire IF pour une repousse de luzerne. $-\varepsilon_{\mathrm{aE}}=1-\mathrm{T}_{\mathrm{E}}-\mathrm{R}_{\mathrm{E}}+\mathrm{R}_{\mathrm{SE}} \times \mathrm{T}_{\mathrm{E}}\left(\mathrm{R}_{\mathrm{SE}}=0,10\right) ; \cdots \varepsilon_{\mathrm{a}}$ $=1-T-R+R_{S} \times T\left(R_{s}=0,15\right)$

b) Variations des efficiences de l'interception de l'énergie utile à la photosynthèse $\varepsilon_{\mathrm{iE}}$ et du rayonnement total $\varepsilon_{\mathrm{i}}$ en fonction de l'indice foliaire pour une repousse de luzerne.

$\longrightarrow \varepsilon_{\mathrm{iE}} ; \cdots-\varepsilon_{\mathrm{i}}$

$\left(\varepsilon_{\mathrm{aE}}\right)$ établie en éclairement énergétique utile à la photosynthèse (EPAR).

Pour justifier l'équivalence de ces efficiences Marshall et Willey (1983), Green (1988) et Russell et al. (1988) admettent l'égalité des coefficients de transmission $T_{E}$ et $T_{Q}$ en se référant au travail de McCartney (1978). En fait cet article correspond à une étude de la composition spectrale du rayonnement global et ne peut être utilisé ici.

Nous avons estimé (Tableau IV) les valeurs des propriétés optiques d'une culture de maïs (indice foliaire 2,6 ) pour quelques conditions (ciel clair - ciel couvert) à partir de la composition spectrale de la lumière (tache de soleil - zone d'ombre) mesurée en énergie (Varlet-Grancher et Bonhomme, 1971) puis convertie en photons (Varlet-Grancher et al., 1981) et de l'étude de la pénétration du rayonnement direct dans la végétation (proportion des taches de soleil et des zones d'ombre; Bonhomme, 1970). Ces résultats semblent montrer que les valeurs obtenues en éclairement quantique sont plus élevées que celles correspondant à l'éclairement énergétique mais les différences restent toujours très faibles (inférieures à $5 \%$ ).

Des mesures de EPAR et QPAR réfléchis et transmis effectuées à l'aide de capteurs ponctuels spécifiques montés sur un chariot mobile dans une culture de maïs confirment les faibles écarts entre $T_{E}$ et $T_{Q}$ (Fig. 4) mais montrent des différences plus importantes entre $R_{E}$ et $R_{Q}$ (Fig. 4) et des valeurs systématiquement plus élevées pour $R_{E}$.

Les mesures de composition spectrale effectuées dans une culture de blé par McCartney et Unsworth (1976) montrent également de faibles variations entre $T_{E}$ et $T_{Q}$. Les variations observées sur les composantes de l'efficience selon l'éclairement considéré (EPAR, QPAR) ne conduisent pas à des différences notables sur $\varepsilon_{\mathbf{a}}$ et $\varepsilon_{\mathrm{i}}$ (Tabl. IV).

Dans un assez grand nombre de publications $T_{E}$ est estimé à partir du coefficient de transmission du rayonnement total $\mathrm{T}$ obtenu à l'aide de pyranomètres linéaires (instrument moins coûteux et surtout d'utilisation plus ancienne). Le

Tableau IV. Propriétés optiques, efficiences de l'absorption et efficiences de l'interception d'une culture de maïs (indice foliaire 2,6) pour l'éclairement énergétique EPAR et quantique QPAR.

\begin{tabular}{|c|c|c|c|c|c|c|c|c|c|c|}
\hline & \multicolumn{2}{|c|}{$\begin{array}{l}\text { Coefficient } \\
\text { de } \\
\text { transmission }\end{array}$} & \multicolumn{2}{|c|}{$\begin{array}{l}\text { Coefficient } \\
\text { de } \\
\text { réflextion } \\
\text { sol-culture }\end{array}$} & \multicolumn{2}{|c|}{$\begin{array}{l}\text { Coefficient } \\
\text { de } \\
\text { réflexion } \\
\text { sol nu humide }\end{array}$} & \multicolumn{2}{|c|}{$\begin{array}{l}\text { Efficience } \\
\text { de } \\
\text { l'absorption }\end{array}$} & \multicolumn{2}{|c|}{$\begin{array}{l}\text { Efficience } \\
\text { de } \\
\text { l'interception }\end{array}$} \\
\hline & $\mathrm{T}_{\mathrm{E}}$ & $\mathrm{T}_{\mathrm{Q}}$ & $\mathrm{R}_{\mathrm{E}}$ & $R_{\mathrm{Q}}$ & $\mathrm{R}_{\mathrm{SE}}$ & $\mathrm{R}_{\mathrm{SQ}}$ & $\varepsilon_{\mathrm{aE}}$ & $\varepsilon_{\mathrm{aQ}}$ & $\varepsilon_{\mathrm{iE}}$ & $\varepsilon_{\mathrm{iQ}}$ \\
\hline \multicolumn{11}{|l|}{ Ciel clair } \\
\hline $\mathrm{h}=24, \mathrm{D} / \mathrm{G}=0,30$ & 0,131 & 0,135 & 0,054 & 0,057 & 0,071 & 0,074 & 0,824 & 0,818 & 0,869 & 0,865 \\
\hline$h=43, D / G=0,23$ & 0,202 & 0,206 & 0,043 & 0,047 & 0,069 & 0,073 & 0,769 & 0,762 & 0,798 & 0,794 \\
\hline$h=64, D / G=0,27$ & 0,288 & 0,291 & 0,032 & 0,033 & 0,070 & 0,074 & 0,700 & 0,697 & 0,712 & 0,709 \\
\hline $\mathrm{h}=71, \mathrm{D} / \mathrm{G}=0,17$ & 0,335 & 0,340 & 0,032 & 0,034 & 0,071 & 0,075 & 0,657 & 0,651 & 0,665 & 0,660 \\
\hline \multicolumn{11}{|l|}{ Ciel couvert } \\
\hline$h=30, D / G=1$ & 0,338 & 0,340 & 0,042 & 0,043 & 0,069 & 0,073 & 0,643 & 0,642 & 0,662 & 0,660 \\
\hline$h=54, D / G=1$ & 0,311 & à,312 & 0,032 & 0,031 & 0,069 & 0,073 & 0,678 & 0,680 & 0,689 & 0,688 \\
\hline
\end{tabular}




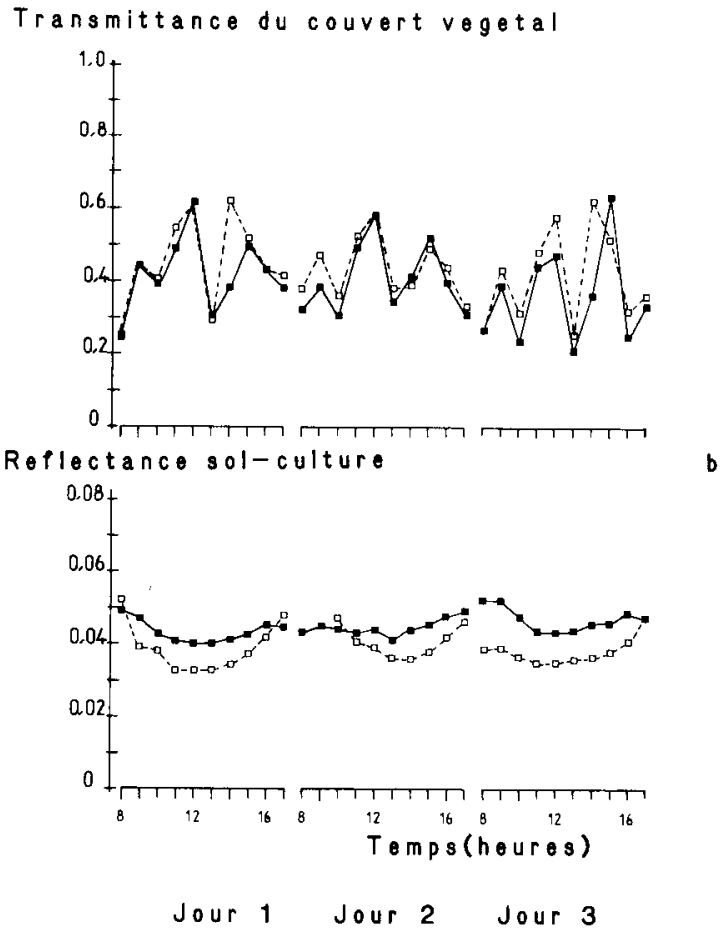

Fig. 4. Variations des transmittances et réflectances (valeurs instantanées) d'une culture de maïs (variété: $X 304 \mathrm{C} I \mathrm{IF}=1,6$ ) pour le rayonnement utile à la photosynthèse au cours de la journée pour trois jours consécutifs.

a) Transmittance du couvert végétal

- éclairement énergétique: $T_{E}=E_{P A R_{t}} / E P A R_{0} ; \rightarrow$ éclairement quantique: $\mathrm{T}_{\mathrm{Q}}=\mathrm{QPAR}_{\mathrm{t}} / \mathrm{QPAR}_{0}$

b) Réflectance sol-culture

-1- éclairement énergétique: $R_{E}=E P A R_{r} / E P A R_{0} ;-$ éclairement quantique: $R_{Q}=Q_{P A R_{r}} /$ QPAR $_{o}$

Tableau $\mathrm{V}$ indique quelques-unes des relations utilisées dans la bibliographie et qui ont été établies par ajustement statistique entre les valeurs expérimentales obtenues pour les deux types de mesure ou, à partir des lois de pénétration du rayonnement dans la végétation et les valeurs de certains paramètres (propriétés optiques et inclinaison des feuilles).

Ces expressions sont valables dans le cas d'un couvert végétal bien alimenté en eau et en éléments minéraux. Dans ces conditions le passage de $T$ à $T_{E}$ n'est peut-être pas toujours nécessaire car l'efficience de l'interception $\varepsilon_{\mathrm{i}}=1$ - $T$ peut fournir une estimation de $\varepsilon_{\mathrm{aE}}$ (Fig. 5 pour une repousse de luzerne); la sous-estimation sur la durée du cycle étant de l'ordre de $10 \%$.

Les relations entre $T$ et $T_{E}$ dépendent de l'inclinaison et surtout des différences de propriétés optiques des feuilles pour les radiations visibles

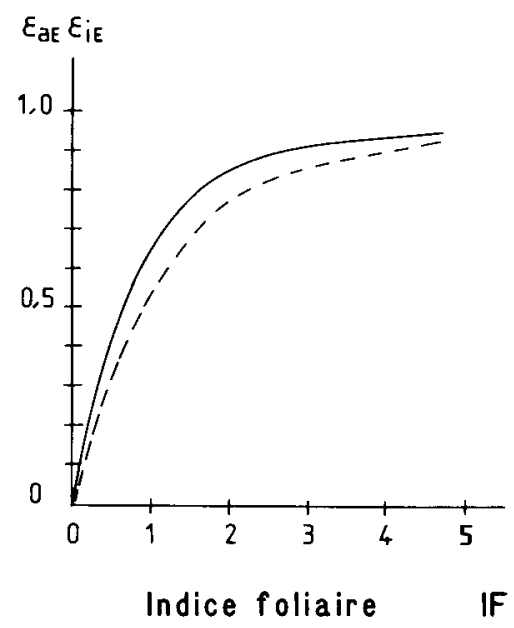

Fig. 5. Variations des efficiences de l'absorption de l'énergie utile à la photosynthèse $\varepsilon_{\mathrm{aE}}$ et de l'interception du rayonnement total $\varepsilon_{i}$ en fonction de l'indice foliaire IF pour une repousse de luzerne.

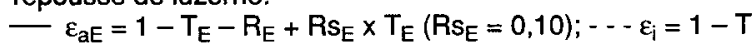

Tableau V. Principales relations utilisées par différents auteurs pour estimer le coefficient de transmission pour le rayonnement utile à la photosynthèse $\left(T_{E}, T_{Q}\right.$, ) à partir du coefficient de transmission pour le rayonnement total $T$.

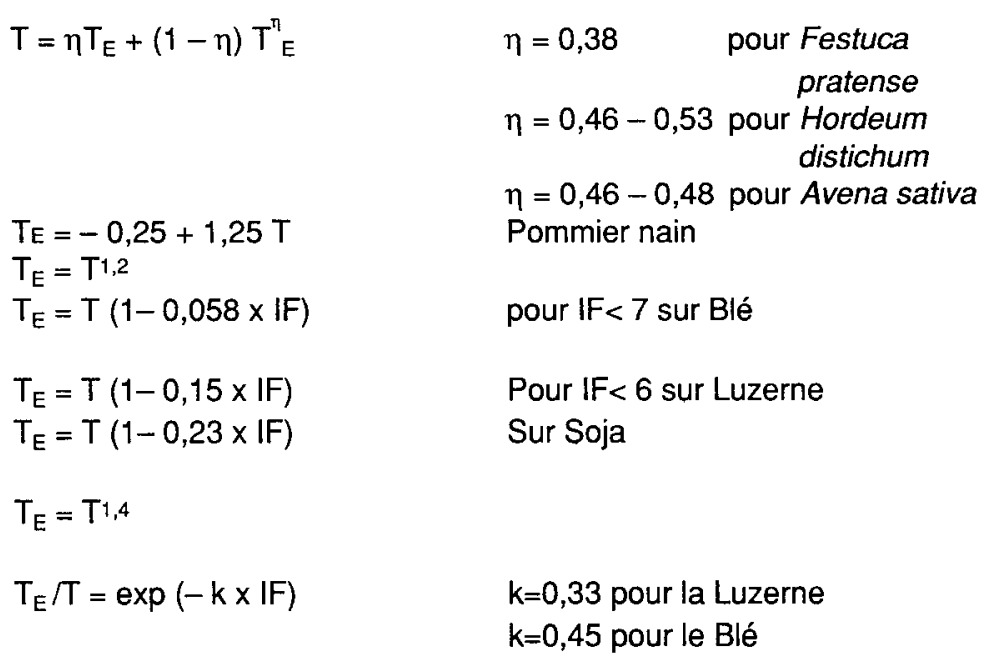

Rodskjer et Kornher (1971); Rodskjer (1972); Kornher et Rodskjer (1974).

Suckling et al. (1975)

Gallagher et Biscoe (1978)

D'après Anderson (1969) in

Varlet-Grancher et al. (1982)

Gosse et al. (1982)

D'après Kumura (1969) in

Gosse et al. (1982)

Marshall et Willey (1983)

Russell et al. (1988)

Gosse (non publié)

Thorne et al. (1988) 
et proche infra-rouge (Fig. 6) qui varient avec l'état hydrique et minéral de la plante (Gaussman, 1985). Ainsi, en conditions limitantes ces relations sont différentes, et les écarts entre $\varepsilon_{\mathrm{aE}}$ et $\varepsilon_{i}$ beaucoup plus importants. Ces relations d'estimation sont maintenant un peu moins utiles avec la commercialisation de capteurs ponctuels et linéaires qui permettent de mesurer les éclairements quantiques.

\section{Estimation du rayonnement absorbé ou inter- cepté par le couvert végétal}

\section{Intégration des mesures du bilan radiatif}

La quantité d'énergie solaire absorbée ou interceptée par un couvert végétal au cours de sa croissance nécessite l'intégration des mesures des différentes composantes du bilan radiatif sur tout le cycle de la culture.

Pour chaque composante l'enregistrement des mesures élémentaires (signaux délivrés par les capteurs) se fait sur une durée et selon une fréquence qui dépendent des caractéristiques des capteurs et des enregistreurs. Ces mesures élémentaires doivent être cumulées sur la période d'intégration choisie : heure, journée, cycle, etc. En fait, le plus souvent ces données sont d'abord intégrées sur un pas de temps variable mais assez court (de quelques minutes à l'heure selon les capacités de stockage des acquisitions de données) pour constituer des valeurs élémentaires qui sont alors cumulées pour la durée des

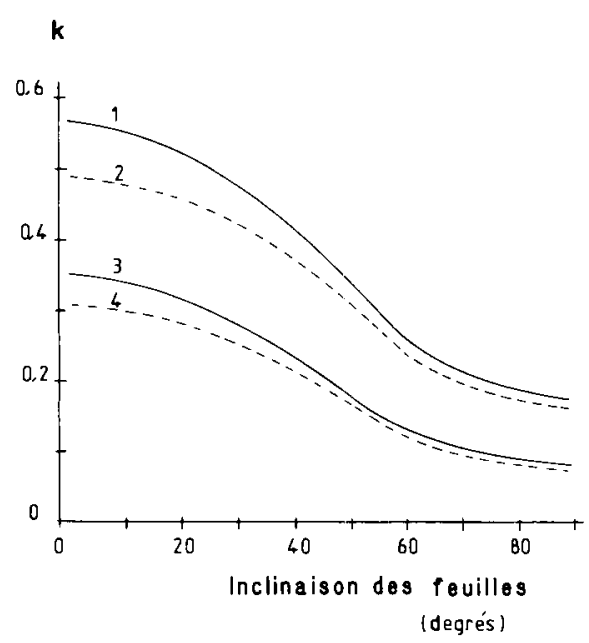

Fig. 6. Relations entre les transmittances du couvert végétal pour l'énergie utile à la photosynthèse $T_{E}$ et pour le rayonnement total $T$. $T_{E} / T=\exp (-k x I F)$

Variations de coefficient $k$ en fonction de l'inclinaison des feuilles pour différentes valeurs des réflectances des feuilles dans la gamme du rayonnement visible $\left(r_{E}\right)$ et dans gamme du rayonnement proche infra-rouge $\left(r_{i R}\right)$ :

$\begin{array}{lrr}\text { - Courbe 1 } & r_{i R}=0,40 & r_{E}=0,05 \\ \text { - Courbe 2 } & 0,40 & 0,10 \\ \text { - Courbe 3 } & 0,50 & 0,05 \\ \text { - Courbe 4 } & 0,50 & 0,10\end{array}$

mesures. Dans la plupart des publications, les auteurs n'indiquent que cette dernière durée.

Les difficultés de maintenance des systèmes de mesure du bilan radiatif et la nécessité de pouvoir obtenir simultanément le rayonnement absorbé par différentes cultures (comparaison de différents traitements agronomiques ou de différents génotypes) conduisent très souvent à effectuer des mesures discontinues. Ainsi dans un grand nombre de travaux (Willcott et al., 1984; Muchow et Coates, 1986; Martin, 1986; Ferraris et Charles-Edwards, 1986 parmi les plus récents), les mesures sont effectuées quelques heures par jour et pour certaines conditions atmosphériques. Pour une culture de soja bien développée, Charles-Edwards et Lawn (1984) utilisent une durée d'intégration de $4 \mathrm{~h}$ autour du midi solaire par ciel clair, et montrent que le coefficient de transmission ainsi obtenu surestime de $10 \%$ seulement la valeur correspondant à une durée d'intégration journalière. Sur blé, Thorne et al. (1988) obtiennent des différences faibles $( \pm$ $1 \%$ ) selon le type de temps (ciel clair - ciel couvert). Toutefois, on peut penser que ces écarts sont plus importants en début de croissance et selon la saison (effet de la position du soleil audessus de l'horizon à midi).

Ces mesures, effectuées en continu ou sur quelques heures de la journée, permettent de calculer l'efficience journalière et d'obtenir le rayonnement absorbé de la journée:

$$
\mathrm{Rg}_{\mathrm{a}}=\varepsilon_{\mathrm{a}} \mathrm{Rg}_{\mathrm{o}}
$$

d'où sur le cycle :

$$
\mathrm{Rg}_{\mathrm{a}}=\Sigma \varepsilon_{\mathrm{a}} \mathrm{Rg}_{\mathrm{o}}
$$

En fait les valeurs journalières de $\varepsilon_{\mathrm{a}}$ sont généralement établies à quelques stades seulement au cours du cycle. Le bilan radiatif est mesuré pendant quelques jours au maximum (souvent deux à trois) selon un intervalle de temps variable mais généralement de 7 à 10 jours, (Sivakumar et Virmani, 1984; Gallo et Daughtry, 1986; Willcott et al., 1984).

Estimation de l'efficience de l'absorption (ou de l'interception) et du rayonnement absorbé (ou intercepté)

Les valeurs journalières de l'efficience $\varepsilon_{\mathrm{a}}, \varepsilon_{\mathrm{i}}$ (rayonnement absorbé ou intercepté) peuvent être corrélées avec l'indice foliaire (IF) du couvert végétal selon des relations du type :

$$
\varepsilon_{\mathrm{a} \text { (valeurs journalieres) }}=\varepsilon_{\mathrm{amax}}[1-\exp (-\mathrm{K} \times \mathrm{IF})]
$$

La valeur maximale de l'efficience d'absorption, $\varepsilon_{\text {amax }}$ (ou d'interception, $\varepsilon_{\text {imax }}$ ) peut être considérée comme une constante (peu différente de 0,95 ) dans les conditions de culture les plus 
courantes. Le coefficient d'absorption journalière du couvert végétal $K$ dépend surtout des propriétés optiques et géométriques du couvert végétal (Varlet-Grancher et Bonhomme, 1979). Si la variabilité de ces caractéristiques optiques et biométriques reste assez faible pour les différents traitements agronomiques étudiés, on peut utiliser une seule relation entre $\varepsilon_{\mathrm{a}}$ et IF établie sur l'une des cultures seulement.

Cette démarche, très courante, n'est pas toujours appliquée à des conditions expérimentales (comparaison de génotypes ayant des ports de plante différents, culture avec ou sans irrigation, etc.) qui permettent de respecter cette hypothèse de stabilité du coefficient d'absorption $\mathrm{K}$. Pour établir ces relations entre l'efficience et l'indice foliaire, les mesures des composantes du bilan radiatif sont effectuées dans une parcelle donnée et généralement rapportées à celles de l'indice foliaire obtenues sur une parcelle proche de celle-ci. Cette méthode suppose une bonne homogénéité de la culture. II est possible aussi de déterminer l'indice foliaire au-dessus des capteurs eux-mêmes après une ou deux journées de mesures radiatives puis de changer leur emplacement et de recommencer l'ensemble des mesures (rayonnement et IF). Le Tableau VI regroupe les valeurs du coefficient $K$ obtenues à partir de l'ajustement entre l'indice foliaire et les efficiences $\varepsilon_{\mathrm{i}}$, $\varepsilon_{\mathrm{a}}$ établies par différents auteurs.

Depuis les travaux de Monsi et Saeki, de nombreux modèles de pénétration du rayonnement solaire dans un couvert végétal ont été développés (cf. les revues de Lemeur et Blad, 1974; Norman, 1975 par exemple); ils permettent de déterminer les différentes formes du rayonnement (diffus, du ciel, direct, et rediffusé) reçu sur un plan horizontal dans la culture et donc de calculer le rayonnement intercepté ou absorbé par le couvert végétal. Parmi les différents types de modèles, ceux basés sur les lois de transferts radiatifs en milieu diffusant (lois de KubelkaMunk, généralisées par Duntley) ont été particulièrement développés depuis quelques années (Allen et Richardson, 1968; Suits, 1972; Verhoef et Bunnik, 1975; Bonhomme et Varlet-Grancher, 1977). Les coefficients introduits dans les équations différentielles (voir Prévot, 1985 par exemple) peuvent être exprimés (Bonhomme et Varlet-Grancher, 1977) en fonction de caractéristiques mesurables du couvert végétal (surface foliaire, propriétés optiques des feuilles, inclinaison des feuilles, etc.).

L'application de ces modèles suppose le respect d'un certain nombre d'hypothèses dont les principales sont:

- l'homogénéité horizontale de la culture,
- la répartition uniforme de l'orientation des feuilles: pas d'azimuts privilégiés,

- l'absence de superposition privilégiée des feuilles les unes par rapport aux autres.

Ils permettent de calculer à chaque instant, pour une longueur d'onde donnée (du spectre solaire) ou une gamme spectrale pour laquelle les caractéristiques optiques du couvert varient peu, le rayonnement absorbé ou intercepté par la végétation et donc son efficience $\varepsilon_{\mathrm{a}}$. Le couvert végétal doit être caractérisé par :

- son indice foliaire,

- l'inclinaison des feuilles,

- les propriétés optiques des feuilles,

- la réflectance du sol sous la culture.

Une des limitations les plus importantes de cette démarche résulte de l'effet de rang (hétérogénéité horizontale) limitation particulièrement importante en début de cycle pour la plupart des plantes cultivées. Cependant à l'échelle des valeurs journalières et pour certaines cultures au moins, l'estimation de l'absorption par ces modèles ne semble pas conduire à des écarts trop importants, comparés aux mesures (cf. Fig. 2 dans Varlet-Grancher et Bonhomme, 1979). II est possible aussi d'utiliser ces modèles en rapportant l'indice foliaire à la surface au sol effectivement occupée par le rang (IF / taux de recouvrement); ce qui revient alors à supposer le respect des hypothèses dans l'espace occupé par le rang. D'autres types de modèles (Prévot, 1985; Sinoquet, 1988) prennent mieux en compte les hétérogénéités de la structure mais leur généralisation dans le cadre de travaux agronomiques est limitée par la difficulté de mesurer certains paramètres.

\section{Conclusion : production de matière sèche et rayonnement absorbé ou intercepté}

Dans un assez grand nombre de travaux publiés ces dernières années, la matière sèche accumulée par le couvert végétal est rapportée au rayonnement absorbé ou intercepté pour quantifier l'efficience de la conversion du rayonnement solaire $\varepsilon_{\mathrm{b}}$. La comparaison des valeurs ainsi obtenues est très difficile (Gosse et al., 1986; Cannell, 1988) en raison, d'une part, de la grande diversité des caractérisations et des mesures ou estimations effectuées, et, d'autre part, du fait de l'insuffisance ou de l'absence d'information sur ces conditions dans beaucoup de publications. II en résulte que les valeurs de $\varepsilon_{b}$ déterminées par certains auteurs n'ont alors d'intérêt que pour ces auteurs eux-mêmes.

Les mesures en éclairement quantique utile à la photosynthèse (QPAR) paraissent actuelle- 
Tableau VI. Valeurs journalières du coefficient $(K)$ obtenu à partir des ajustements entre les efficiences d'interception ou d'absorption du rayonnement $\left(R_{g}\right.$, EPAR, QPAR) et l'indice foliaire selon des relations de type :

$$
\varepsilon=\varepsilon_{\max }[1-\exp (-K \times \mid F)]
$$

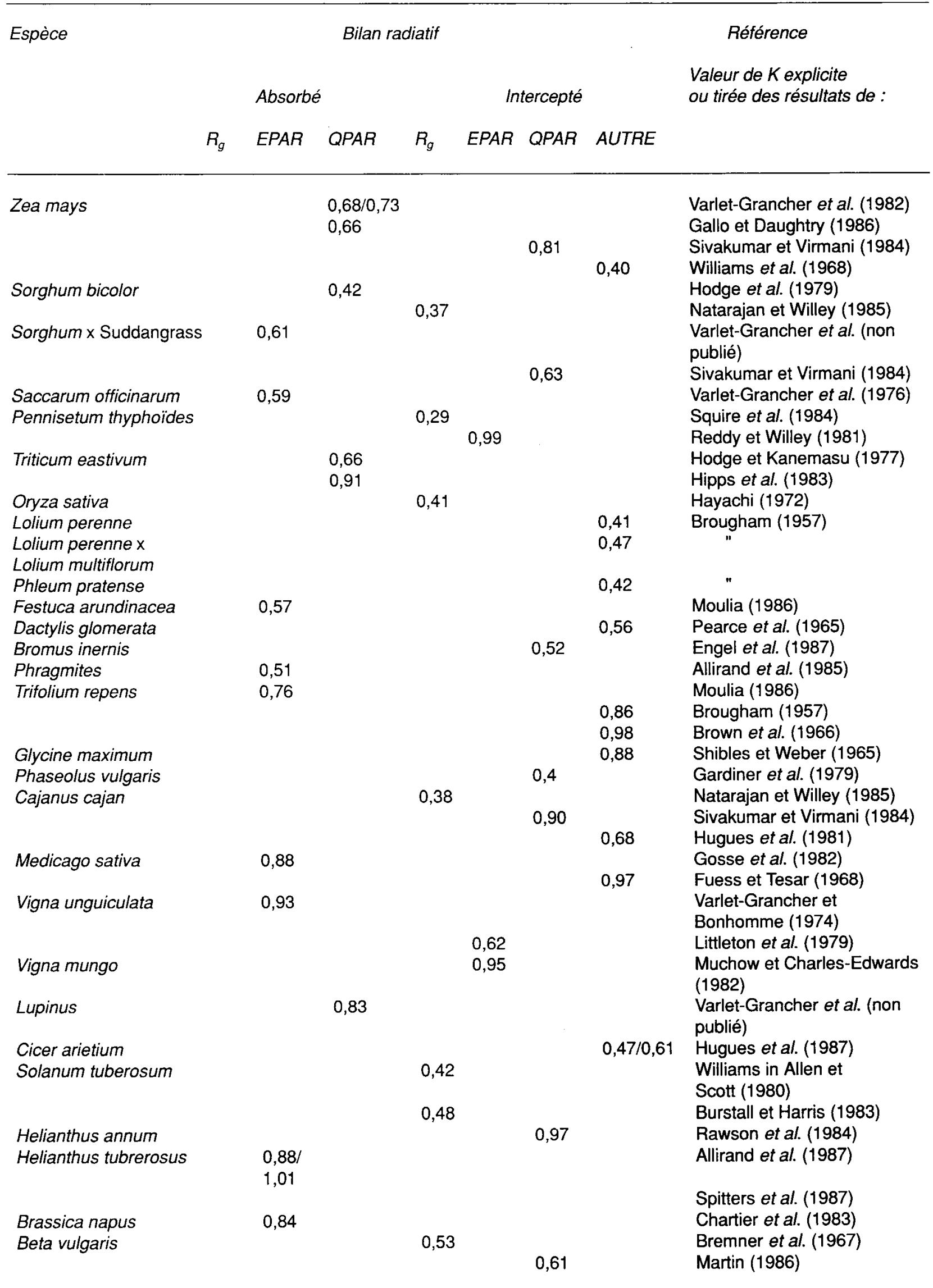


ment les plus fiables et les plus faciles à réaliser puisqu'il existe des instruments spécifiques (capteurs ponctuels et linéaires) pour obtenir les différentes composantes du bilan radiatif. Ces mesures permettent de calculer le rayonnement quantique absorbé $\left(\mathrm{QPAR}_{\mathrm{a}}\right)$ ou intercepté $\left(Q P A R_{i}\right)$ et d'estimer les quantités d'éclairement énergétique $\operatorname{EPAR}_{\mathrm{a}}\left(\approx \varepsilon_{\mathrm{aQ}} \times \mathrm{XPAR}_{0}\right)$ et $\operatorname{EPAR}_{\mathrm{i}}$ $\left(\approx \varepsilon_{i Q} \times E P A R_{0}\right)$. Le coût des capteurs nécessaires reste assez élevé et constitue une limitation à leur utilisation, même si l'efficience de l'interception $\left(\varepsilon_{\mathrm{iQ}}\right)$, peu différente de l'efficience de l'absorption $\left(\varepsilon_{\mathrm{aQ}}\right)$, peut être seulement considérée. Les autres méthodes (efficience de l'interception du rayonnement total, absorbé selon Gallagher et Biscoe, estimation de $T_{E}$ ou $T_{Q}$ à partir de T...) peuvent conduire à des différences importantes sur les valeurs de $\varepsilon_{b}$, si les caractéristiques du couvert végétal (inclinaison et propriétés optiques des feuilles, propriétés optiques du sol) varient beaucoup avec les conditions expérimentales (génotype, disponibilités en eau et en éléments minéraux) et si l'indice foliaire est faible (phase d'installation du système foliaire notamment). Pour ces situations une détermination correcte du bilan radiatif apparaît nécessaire, mais devant la difficulté de mesurer le rayonnement transmis, on peut se demander si l'utilisation des modèles d'interception les plus simples n'est pas plus intéressante; leurs résultats n'étant pas moins précis que ceux des mesures ellesmêmes.

Le développement des techniques de télédétection a conduit à de nombreux travaux sur des relations entre des combinaisons de la réflectance du couvert végétal pour différentes gammes spectrales (indices de végétation) et les efficiences d'interception ou d'absorption du PAR (Daughtry et al., 1983; Hatfield et al., 1984; Allirand et al., 1988;). Ces indices varient fortement pendant la phase d'implantation du couvert végétal mais l'instabilité des relations obtenues ainsi que la mise en œuvre de ces méthodes rendent l'estimation de $\varepsilon_{\mathrm{i}}$ ou de $\varepsilon_{\mathrm{a}}$ encore difficile.

\section{Références}

Allen E.J. \& Scott R.K. (1980) An analysis of growth of the potato crop. J. Agric. Sci. 94, 583-606

Allen W.A. \& Richardson A.J. (1968) Interaction of light with a plant canopy. J. Opt. Soc. Am. 58, 8, 1023-1028

Allirand J.M., Chartier M. \& Gosse G. (1985) Productivité du roseau pragmites. In: Energy from Biomass (Palz W., Coombs J. \& Hall D.O., eds), 3rd E.C. conference C.C.E., Venise (ITA), 25-29 Mars 1985, Elvesier Applied Sci. Publ. (GBR) 321-322

Allirand J.M., Chartier M. \& Gosse G. (1987) Productivité potentielle, réelle et modélisation de la production d'une culture de topinambour. In: Jerusalem Artichoke
Workshop. E.C.C. Madrid (ESP), 29 Septembre-01 Octobre 1987

Allirand J.M., Chartier M. \& Gosse G. (1988) Estimation de l'efficience de l'interception d'un couvert de luzerne à partir d'un indice foliaire de végétation. In: Signatures Spectrales d'objets en Télédétection, 4e coll. Int., CNES, INRA, ESA, ISPRS, CNRS, Aussois (FRA) 18-22 Janvier 1988, 163-166

Anderson M.C. (1971) Radiation and crop structure. In: Plant Photosynthetic Production, Manual of Methods. Ed. Z. Sestak, J. Catsky et P.G. Jarvis, Dr W. Junk Publ. - The Hague, 412-466

Asrar G., Hipps L.E. \& Kanemasu E.T. (1984) Assessing solar energy and water use efficiencies in winter wheat : a case study. Agric. For. Meteorol. 31, 47-58

Baille A., Bonhomme R., Durand R. \& Mermier M. (1982) Mémento rayonnement. Note interne INRA, $60 \mathrm{p}$.

Baker D.N. \& Musgrave R.B. (1964) Photosynthesis under field conditions. $V$ - Further plant chamber studies of the effects of light on corn (Zea mays 1.). Crop. Sci. 4, 2, 127-131

Bell C.J. \& Rose D.A. (1981) Light measurement and the terminology of flow. Plant Cell. Environment. 4, 8996

Berglund E.R. \& Mace A.C. (1972) Seasonal albedo variation of Black spruce and Sphagnum - Sedge bog cover types. J. Appl. Meteorol. 11, 5, 806-812

Bingham M.J. \& Long S.P. (1985) Equipment for field and laboratories studies of whole plant and crop photosynthesis and productivity research. In: Techniques in Bioproductivity and Photosynthesis. (J. Coombs, D.O., Hall, S.P. Long, J.M.O. Scurlock eds.) 2nd ed.. Pergamon Press pp. 229-272

Blackburn W.J. \& Proctor J.T.A. (1983) Estimating photosynthetically active radiation from measured solar irradiation. Solar energy 31, 2, 233-234

Bonhomme R. (1970) Surface relative des taches de soleil dans la végétation. In: Techniques d'Etude des Facteurs Physiques de la Biosphère. INRA, Paris, 99-104

Bonhomme R. \& Varlet-Grancher C. (1977) Application aux couverts végétaux des lois de rayonnements en milieu diffusant. 1 - Etablissement des lois et vérifications expérimentales. Ann. Agron. 28, 6, 567-582

Bonhomme R., Ruget F., Derieux M. \& Vincourt P. (1982) Relations entre productions de matière sèche aérienne et énergie interceptée chez différents génotypes de maïs. C.R. Acad. Sci., Paris, série III, 294, 393-398

Bremner P.M., El Saeed E.A.K. \& Scott R.K. (1967) Some aspects of competition for light in potatoes and sugar beet. J. Agric. Sci. Camb. 69, 283-290

Britton C.M. \& Dodd J.D. (1976) Relationships of photosynthetically active radiation and shortwave irradiance. Agric. Meteorol. 17, 1-7

Brougham R.W. (1957) Interception of light by the foliage of pure and mixed stands of pasture plants. Aust. J. agric. Res. 39-52

Brown G.W. (1973) Measuring transmitted global radiation with fixed and moving sensors. Agric. Meteorol. 11, 1, 115-121

Brown K.W., Rosenberg N.J. \& Doraiswamy P.C. (1970) Shading inverted pyranometers and measurement of radiation reflected from alfalfa crop. Water Res. 6, 6, 1782-1786 
Brown R.H., Blaser R.E. \& Dunton H.L. (1966) Leaf area index and apparent photosynthesis under various microclimates for different pasture species. Proc. 10th Int. Grassland Cong., Helsinki 108-113

Burstall L. \& Harris P.M. (1983) The estimation of percentage light interception from leaf area index and percentage ground cover in potatoes. J. agric. Sci. Camb. $100,241-244$

Cannell M.G. (1988) The scientific background. In: Biomass Forestry in Europe: a Strategy for the Future. (Hummel F.C., Palz W., Grassi G. eds) Elsevier Applied Sci. pp. 83-140

Charles-Edwards D.A. \& Lawn R.J. (1984) Light interception by grain legume row crops. Plant Cell. Env. 7 , 247-251

Chartier M., Fabre B., Gosse G. \& Rode J.C. (1983) Bilan radiatif d'un couvert de colza. 6e Congrès Colza, Paris, mai 1983, 154-165

Chartier P. (1966) Etude du microclimat lumineux dans la végétation. Ann. Agron. 17, 5, 571-602

Chartier P., Perrier A. \& Verbrugghe M. (1971) Assimilation nette, utilisation de l'eau et microclimatologie d'un champ de maïs. I - Objectifs et présentation du dispositif expérimental de la lumière. Ann. Agron. 22, 4, 367-381

Clark J.B. \& Lister E.R. (1975) Photosynthetic action spectra of trees. 1 - Comparative photosynthetic action spectra of one deciduous and four coniferous tree species as related to photorespiration and pigment complements. Plant Physiol. 55, 401-406

Combres J.C., Bonhomme R., Baldy Ch., Goillot Ch. \& de Parcevaux S. (1970) Un pyranomètre linéaire destiné à la mesure du rayonnement sous couvert végétal. In: Techniques d'Etude des Facteurs Physiques de la Biosphère. (M. Hallaire, $\mathrm{C}$. Perrin de Brichambaut et Ch. Goillot eds) INRA Publ, 59-70

Daughtry C.S.T., Gallo K.P. \& Bauer M.E. (1983) Spectral estimates of solar radiation intercepted by corn canopies. Agron. J. 75, 527-531

Engel R.K., Moser L.E., Stubbendieck J. \& Lowry S.R. (1987) Yield accumulation, leaf area index and light interception of smooth Bromegrass. Crop Sci. 2, 27, 316-321

Ferraris R. \& Charles-Edwards D.A. (1986) A comparative analysis of the growth of sweet and forage Sorghum crops. I - Dry matter production, phenology and morphology. Aust. J. Agric. Res. 37, 495-512

Flowers E.C. \& Helfert N.F. (1966) Laboratory and field investigations of Eppley radiation sensors. Monthly Weather Rev. 94, 259-264

Foale M.A., Wilson G.L., Coates D.B. \& Haydock K.P. (1984) Growth and productivity of irrigated Sorghum bicolor (L. Moench) in Northern Australia. II - Low solar altitude as a possible seasonal constraint to productivity in the tropical dry season. Aust. J. Agric. Res. 35, 229-238

Fritschen L.J. \& Gay L.W. (1979) Environmental Instrumentation. Springer, New York

Fuess F.W. \& Tesar M. (1968) Photosynthetic efficiency, yields and leaf loss in alfalfa. Crop. Sci. 8, 159-163

Fuchs M., Stanhill G \& Moreshet S. (1976) Effect of increasing foliage and soil reflectivity on the solar radiation balance of wide-row grain sorghum. Agron. J. 68, 865-871

Gaastra P. (1959) Photosynthesis of crop plants as influenced by light, carbon dioxide, temperature and stomatal diffusion resistance. Meded. Landbouwhogeschool Wegeningen 59, 13, 1-68

Gabrielsen E.K. (1940) Einfluss der Lichtfaktoren auf die Kohlensäureassimilation der Laubblätter. Dansk. Botan. Arkiv. 10, 1, 1-177

Gallagher J.N. \& Biscoe P.V. (1978) Radiation absorption, growth and yield of cereals. J. agric. Sci. Camb., $91,47-60$

Gallo K.P. \& Daughtry C.S.T. (1986) Techniques for measuring intercepted and absorbed photosynthetically active radiation in corn canopies. Agron. J. 78, 752756

Gardiner T.R., Vietor D.M. \& Craker L.E. (1979) Growth habit and row width effects on leaf area development and light interception of field beans. Can J. Plant Sci. 59, 191-199

Gaussman H.W. (1985) Plant leaf optical properties. Texas Tech. Press, Lubbock, Texas

Gosse G., Chartier M., Varlet-Grancher C. \& Bonhomme R. (1982) Interception du rayonnement utile à la photosynthèse chez la luzerne : variations et modélisation. Agronomie 2, 6, 583-588

Gosse G., Chartier M. \& Lemaire G. (1984) Mise au point d'un modèle de prévision de production pour une culture de luzerne. C.R. Acad. Sci. Paris, Série III, 298, 541-544

Gosse G., Varlet-Grancher C., Bonhomme R., Chartier M., Allirand J.M. \& Lemaire G. (1986) Production maximale de matière sèche et rayonnement solaire intercepté par un couvert végétal. Agronomie 6, 1, 47-56

Green C.F. (1988) Using observations of radiation transmitted through crop canopies to analyse stand growth. DELTA-T DEVICES, Applications note, apl-3, $5 p$

Hatfield J.L. \& Carlson R.E. (1978) Photosynthetically active radiation, $\mathrm{CO} 2$ uptake and stomatal diffusive resistance profiles within soybean canopies. Agron. J. 70, 592-596

Hatfield J.L., Asrar G. \& Kanemasu E.T. (1984) Intercepted photosynthetically active radiation estimated by spectral reflectance. Remote Sens. Environ. 14, 65-75 Hayachi K. (1972) Efficiencies of solar energy conversion in rice varieties. Bull. Nat. Ist. Agric. Sci. 23, 1-67

Hipps L.E., Asrar G. \& Kanemasu E.T. (1983) Assessing of photosynthetically active radiation in winter wheat. Agric. Meteorol. 28, 253-259

Hodge T. \& Kanemasu E.T. (1977) Modeling daily matter production of winter wheat. Agron. J. 974-978

Hodge T., Kanemasu E.T. \& Teare J.D. (1979) Modeling dry matter accumulation and yield of grain sorghum. Can. J. Plant Sci. 59, 803-818

Holmes M.G., Klein W.H. \& Sager J.C. (1985) Photons, flux and some light on philology. Horscience, 20 (1), 29-31

Howell T.A. \& Musik T.T. (1984) Relationship of dry matter production of field crops to water consumption. In: Les Besoins en Eau des Cultures Paris, 11-14 Septembre 1984. (A. Perrier, C. Riou eds.) INRA, 247-269 Howell T.A., Meek D.W. \& Hatfield J.L. (1983) Relationship of photosynthetically active radiation to shortwave radiation in the San Joaquim Valley. Agric. Meteorol. 28, 157-175

Hugues G., Keating J.D.H. \& Scott S.P. (1981) Pigeon pea as a dry season crop in Trinidad, West Indies. II - 
Interception and utilization of solar radiation. Trop. Agric. 191-199

Hugues G., Keating J.D.H., Cooper P.J.M. \& Dee N.F. (1987) Solar radiation interception and utilization by chick pea (Cicer arietinum L.) crops in northern Syria. J. agric. Sci. Camb. 108, 419-424

Inada K. (1978) Photosynthetic enhancement spectral in higher plants. Plant and Cell. Physiol. 19, 6, 10071017

Incoll L.D., Long S.P. \& Ashmore M.R. (1977) S.I. units in publications in plant science. Curr. adv. Plant Sci. $28,331-342$

Kamel M.S. (1958) Efficiency of solar conversion as related with growth in barley. Meded. Landbouwhogeschool. Wegeningen 58, 8, 1-9

Kalma J.D. \& Badham R. (1972) The radiation balance of a tropical pasture. I- The reflection of shortwave radiation. Agric. Meteorol. 10, 251-259

Khurana S.C. \& McLaren J.S. (1982) The influence of leaf area, fight interception and season on potato growth and yield. Potato Res. 25, 329-342

Kornher A. \& Rodskjer N. (1967) Uber die Bestimmung der Globaldrahlung in Pflanzenbeständen. Flora $B$ 157, 149-164

Kornher A. \& Rodskjer N. (1974) Determination of PAR in oats from records of global radiation. Swedish $J$. agric. Res. 4, 167-175

Krizek D.T. \& McFarlane J.C. (1983) Controlled environment guidelines. Hortscience 18 (5), 662-664

Kubin S. (1971) Measurement of radiant energy. In: Plant photosynthetic Production. Manual of Methods. (Z. Sestak, J. Catsky \& P.G. Jarvis, eds.) Junk, The Hague, pp. 702-765

Laisk A. (1969) Measurement of plant cover transparency. In: Photosynthetic Productivity of Plant Stand. Inst. Phys. and Astron. Acad. Sci. ESSR, Tartu, 174185

Lemeur R. \& Blad B.L. (1974) A critical review of light models for estimating the shortwave radiation regime of plant canopies. Agric. Meteorol. 14, 255-286

Littleton E.J., Dennet M.D., Monteith J.L. \& Elston E.L., (1979) The growth and development of cowpeas (Vigna unguiculata) under tropical field conditions. 2Accumulation and partition of dry weight. J. agric. Sci., Camb. 93, 309-320

Luxmoore R.J., Millington R.J. \& Aston A.R. (1971) Modified tube solarimeters for additive and net measurements of visible infrared and solar radiation. Agron. J. 63 (2), 329-330

Marshall B. \& Willey R.W. (1983) Radiation interception and growth of pearl millet/groundnut. Field Crops Res., 7, 141-160

Martin R.J. (1986) Radiation interception and growth of sugar beet at different sowing dates in Canterbury. N. Z. J. Agric. Research 29, 381-390

Matthews R.B. \& Saffell R.A. (1987) An instrument to measure light distribution in row crop. Agric. For. Meteorol. 39, 177-184

McCartney H.A. (1978) Spectral distribution of solar radiation. II- Global and diffuse. Quart. J.R. Met. Soc. $104,911-926$

McCarteney H.A. \& Unsworth M.H. (1976) A spectroradiometer for measuring the spectral radiation in plant canopies. In: Light as an Ecological Factor: II. 16th
Symp. British Ecol. Soc., 26-28 March 1974, (G.C. Evans, R. Bainbridge, O. Rackhar, eds.) Blackwell, New York, pp. 565-568

McCree K.J. (1966) A solarimeter for measuring photosynthetically active radiation. Agric. Meteorol. 3, 353366

McCree K.J. (1972) The action spectrum, absorptance and quantum yield of photosynthesis in crop plants. Agric. Meteorol. 9, 191-216

McCree K.J. (1973) The measurement of photosynthetically active radiation. Solar energy 15, 83-87

McKinnon J.C., Gartley C.H. \& Wilkie K.J. (1978) Energy efficiency of forage maize production in an Atlantic Canadian environment. J. Appl. Ecol. 15, 503514

McLaren J.S. (1980) The expression of light measurements in relation to crop research. Seed Prod. 663670

Meek D.W., Hatfield J.L., Howell T.A., Idso S.B. \& Reginato R.J. (1984) A generalized relationship between photosynthetically active radiation and solar radiation. Agron. J. 76, 939-945

Mohr H. \& Schafer E. (1979) Uniform terminology for radiation: a critical comment. "Quest editorial", Photochem. Photobiol. 29, 1061-1062

Monteith J.L. (1972) Solar radiation and productivity in tropical ecosystems. J. Appl. Ecol. 9, 747-766

Moulia B. (1986) Contribution à l'étude écophysiologique de la fétuque élevée, du trèfle blanc et de leur association. Mém. ENITA de Bordeaux

Muchow R.C. \& Charles-Edwards D.A. (1982) A physiological analysis of growth of mungbeans at a range of plant densities in tropical Australia. I. Dry matter production. Aust. J. Agric. Res. 33, 41-51

Muchow R.C. \& Coates D.B. (1986) An analysis of the environmental limitation to yield of irrigated grain sorghum during the dry season in tropical Australia using a radiation interception model. Aust. J. Agric. Res. 37, 135-148

Nagaraja Rao C.R. (1984) Photosynthetically active components of global solar radiation : measurements and model computations. Arch. Met. Geoph. Biocl., ser. $B, 34,353-364$

Natarajan M. \& Willey R.W. (1985) Effects of row arrangement on light interception and yield in sorghum - pigeon pea intercropping. J. agric. Sci., Camb. 104 263-270

Nichiporovich A.A. (1960) Conference on measurement of visible radiation in plant physiology, agrometeorology and ecology. Fizid. Rast. 7, 744-747

Norman J.M. (1975) Radiative transfer in vegetation. In: Heat and Transfert in the Biosphere. Transfer Procresses in Plant Environment. (D.A. de Vries \& N.H. Afgan, eds) Scripta Washington D.C., pp. 87-205

Norris D.J. (1974) Calibration of pyranometers in inclined and inverted positions. Solar Energy, 16, 53-55

Pearce R.B., Brown R.H. \& Blaser R.E. (1965) Relationships between leaf area index, light interception and net photosynthesis in orchardgrass. Crop Sci. 5, $6,553-556$

Pech G. (1986) Mobile sampling solar radiation under conifers. Agric. For. Meteorol. 37, 15-28

Pereira A.R., Machado E.C. \& Camargo M.B.P. (1982)

Solar radiation regime in three cassava (Manihot escu- 
lenta Crantz) canopies. Agric. Meteorol. 26 , $1-10$

Perrin de Brichambaut Ch. (1963) Rayonnement Solaire et Echanges Radiatifs Naturels. Gauthier-Villars, Paris

Prévot L. (1985) Modélisation des échanges radiatifs au sein des couverts végétaux. Application à la télédétection, validation sur un couvert de maîs. Thèse Université Paris VI

Rawson H.M., Dunstone A.L., Long M.J. \& Begg J.E. (1984) Canopy development, light interception and seed production in sunflower as influenced by temperature and radiation. Aust. J. PLant. Physiol. 11, 255265

Reddy M.S., Willey R.W. (1981) Growth and ressource use studies in an intercrop of pearl millet/groundnut. Field Crops Res. 4, 13-24

Reifsnyder W.E., Furnival G.M. \& Horowitz J.L. (1971) Spatial and temporal distribution of solar radiation beneath forest canopies. Agric. Meteorol. 9, 23-27

Robinson N. (1966) Solar Radiation. Elsevier, Amsterdam

Rodskjer N. (1972) Measurements of solar radiation in barley and oat. Swedish J. agric. Res. 2, 71-81

Rodskjer N. \& Kornher A. (1971) Uber die Bestimmung der Strahlungsenergie im Wellenlängenbereich von $03-$ $07 \mu$ in Pflanzenbeständen. Agric. Meteorol. 8, 2, 139150

Russell G., Jarvis P.G. \& Monteith J.C. (1988) Absorption of radiation by canopies and stand growth. $\mathrm{I} n$ : Plant canopies: their growth, form and function. (G. Russell, B. Marshall and P.G. Jarvis eds) Cambridge CUP

Sager J.C., Edwards J.L. \& Klein W.H. (1982) Light energy utilization efficiency for photosynthesis. Transaction of ASAE, 1737-1746

Savage M.J. (1979) Terminology pertaining to photosynthesis. "Letter to the editor". Crop Sci. 19, 3, 424

Savage M.J. (1982) Radiation in plant research: a plea for standardization. Hortscience 17, 2, 134-135

Sheehy J. (1985) Radiation. In: Instrumentation for Environmental Physiology. Soc. for Exp. Biol. Seminar 22, (B. Marshall F.I. Woodward eds,) Cambridge University Press, Cambridge, pp. 5-28

Shibles R. (1976) Terminology pertaining to photosynthesis. Comittee report., Crop Sci 16, 437-439

Shibles R.M. \& Weber C.R. (1965) Leaf area, solar radiation interception and dry matter production by soybeans. Crop Sci. 5, 575-577

Sinclair T.R. \& Lemon E.R. (1974) Penetration of photosynthetically active radiation in corn canopies. Agron. J. 66, 201-204

Sinclair T.R., Desjardins R.L. \& Lemon E.R. (1974) Analysis of sampling errors with traversing radiation sensors in corn canopies. Agron. J. 66, 214-217

Sinoquet H. (1988) Modélisation des échanges radiatifs de courte longueur d'onde dans certains couverts hétérogènes. Thèse de Docteur Ingénieur, INRA ParisGrignon, 20 mai 1988

Sivakumar M.V.K. \& Virmani S.M. (1984) Crop productivity in relation to interception of photosynthetically active radiation. Agric. For. Meteorol. 31, 131-141

Slatyer R.O. \& Mcllroy I.C. (1961) Practical microclimatology. CSIRO, Melbourne
Spitters C.J.T., Lootsma M. \& Van de Waart M. (1987) The constrasting growth pattern of early and late varieties in Helianthus tuberosus. In: Jerusalem Artichoke Workshop EEC Madrid (ESP), 29 Septembre-01 Octobre. Elsevier, Amsterdam

Squire G.R., Marshall B., Terry A.C. \& Monteith J.L. (1984) Response to temperature in a stand of pearl millet. VI- Light interception and dry matter production. J. Exp. Bot. 35, 153, 599-610

Stanhill G. \& Fuchs M. (1977) The relative flux density of photosynthetically active radiation. J. appl. Ecol. 14, 317-322

Stanhill G., Cox J.T.H. \& Moreshet S. (1968) The effect of crop and climate factors on the radiation balance of an irrigated maïze crop. J. appl. Ecol. 5, 707-720

Stanhill G., Fuchs M. \& Oguntoyimbo J. (1971) The accuracy of field measurements of solar radiation reflectivity. Arch. Met. Geoph. Biokl. ser. B, 19, 113132

Stigter C.J. \& Musabilha V.M.M. (1982) The conservative ratio of photosynthetically active to total radiation in the tropics. J. appl. Ecol. 19, 853-858

Suckling P.W., Davies J.A. \& Proctor J.T.A. (1975) The transmission of global and photosynthetically active radiation within a dwarf apple orchard. Can J. Bot. 53, $16,1428-1441$

Suits G. (1972) The calculation of the directional reflectance of a vegetative canopy. Remote Sens. Environ. 2, 117-125

Suraqui S., Goldberg B. \& Klein W.H. (1977) An analysis of the errors found in broadland filter radiometry. Solar energy 19, 123-127

Szeicz G. (1974) Solar radiation for plant growth. $J$. appl. Ecol. 11, 2, 617-636

Szeicz G., Monteith J.L. \& Dos Santos J.M. (1964) Tube solarimeter to measure radiation among plants. J. appl. Ecol. 1, 169-174

Thimijan R.W. \& Heins R.D. (1983) Photometric, radiometric and quantum light units of measure: a review of procedures for interconversion. Hortscience 18 (6), 818-822

Thorne G.N., Pearman I., Day W. \& Todd A.D. (1988) Estimation of radiation interception by winter wheat from measurements of leaf area. J. agric. Sci., Camb., $110,101-108$

Varlet-Grancher C. (1974) Assimilation nette, utilisation de l'eau et microclimat d'un champ de maïs. VQuantité et qualité de la lumière solaire réfléchie. Ann. Agron. 25 (6), 797-810

Varlet-Grancher C. (1975) Variation et estimation de l'énergie d'origine solaire reçue sur des plans d'inclinaison et d'azimut variables. Ann. Agron. 26 (3), 245264

Varlet-Grancher C. \& Bonhomme R. (1971) Assimilation nette, utilisation de l'eau et microclimat d'un champ de maïs. III. Composition spectrale de la lumière dans la culture. Ann. Agron. 22, 5, 515-525

Varlet-Grancher C. \& Bonhomme R. (1974) Utilisation de l'énergie solaire par une culture de Vigna sinensis. III- Evolution du rendement énergétique pendant la phase végétative. Ann. Agron. 25 (6), 811-819

Varlet-Grancher C. \& Bonhomme R. (1979) Application aux couverts végétaux des lois de rayonnements en milieu diffusant. II- Interception de l'énergie solaire par une culture. Ann. Agron. 30, 1-26 
Varlet-Grancher C., Bonhomme R. \& Castaneda P. (1976) Rendimento energetico de un cultivo de cana de azucar. Turrialba, 26, 2, 139-143

Varlet-Grancher C., Chartier M., Gosse G. \& Bonhomme R. (1981) Rayonnement utile pour la photosynthèse des végétaux en conditions naturelles: caractérisation et variations. $C_{\text {Ecol. }}$ Plant. 2, 16, 2, 189-202

Varlet-Grancher C., Bonhomme R., Chartier M. \& Artis $P$. (1982) Efficience de la conversion de l'énergie solaire par un couvert végétal. CEcol. Plant. 3, 17, 1, 3-26

Verhoef W. \& Bunnik N.J.J. (1975) A model Study on the Relations between Crop Characteristic and Canopy Spectral Reflectance, Niwars, Delft

Vidovic J. (1975) A device for the measurements of radiation in stands with automatically moving sensors. Biol. Plant. 17, 1, 75-78
Weiss A. \& Norman J.M. (1985) Partitioning solar radiation into direct and diffuse, visible and near infrared components. Agric. For. Meteorol. 34, 205-213

Willcott J., Herbert S.J. \& Liu Zhi-Yi (1984) Leaf area display and light interception in short season soybeans. Field Crops Res. 9, 173-182

Williams M.A. \& Austin R.B. (1977) An instrument for measuring the transmission of short wave radiation by crop canopies. J. appl. Ecol. 14, 987-992

Williams W.A., Loomis R.S. \& Lepley C.R. (1968) Vegetative growth of corn as affected by population density. 1 - Productivity in relation to interception of solar radiation. Crop Sci. 5, 211-215

Yates D.J. \& Steven M.D. (1987) Reflexion and absorption of solar radiation by flowering canopies of oil-seed rape (Brassica napus L.). J. agric. Sci., Camb., 109, 495-502 